\title{
Competition Problems and Governance of Non- personal Agricultural Machine Data: Comparing Voluntary Initiatives in the US and EU
}

\author{
by Can Atik and Bertin Martens*
}

\begin{abstract}
The arrival of digital data in agriculture opens the possibility to realise productivity gains through precision farming. It also raises questions about the distribution of these gains between farmers and agricultural service providers. Farmers' control of the data is often perceived as a means to appropriate a larger share of these gains. We show how data-driven agricultural business models lock farm data into machines and devices that reduce competition in downstream agricultural services markets. Personal data protection regulation is not applicable to non-personal agricultural machine data. Voluntary data charters in the EU and US emulate GDPRlike principles to give farmers more control over their data but do not really change market-based outcomes due to their legal design. Third-party platforms are a necessary intermediary because farmers cannot achieve the benefits from applications that depend on economies of scale and scope in data aggregation. Data lock-in, combined with the low mar-
\end{abstract}

\begin{abstract}
ginal value of individual farm data, puts farmers in a weak bargaining position. Neutral intermediaries that are not vertically integrated into agricultural machines, inputs or services may help farmers to circumvent monopolistic data lock-ins. However, unless these neutral intermediaries find a way to generate and monetise economies of scale and scope with their data, their business model may not be sustainable. Regulatory intervention that facilitates portability and interoperability might be useful for farmers to overcome data lock-ins, but designing data access rights is a complicated issue as many parties contribute data in the production process and may claim access rights. Minor changes in who gets access to which data under which conditions may have significant effects on stakeholders. We conclude that digital agriculture still has some way to go to reach equitable and efficient solutions to data access rights. Similar situations are likely to occur in other industries that rely on non-personal machine data.
\end{abstract} competition policy

๑ 2021 Can Atik and Bertin Martens

Everybody may disseminate this article by electronic means and make it available for download under the terms and conditions of the Digital Peer Publishing Licence (DPPL). A copy of the license text may be obtained at http://nbn-resolving. de/urn:nbn:de:0009-dppl-v3-en8.

Recommended citation: Can Atik and Bertin Martens, Competition Problems and Governance of Non-personal Agricultural Machine Data: Comparing Voluntary Initiatives in the US and EU, 12 (2021) JIPITEC 370 para 1

\section{A. Introduction}

1 In conventional agriculture, decisions on farm inputs and processes are taken by farmers, based on their personal know-how. Today, the introduction of sensor-based digital data, Internet-of-Things (IoT) technologies and big data analytics in Smart Farming or Digital Agriculture ${ }^{1}$ result in machine-

* Can Atik is a PhD candidate at Tilburg Law School with affiliation to the Tilburg Law and Economics Center (TILEC) and Tilburg Institute for Law, Technology, and Society (TILT),
5037 DE Tilburg, the Netherlands. The PhD research is funded by the postgraduate scholarship program of the Ministry of National Education, Republic of Turkey. Bertin Martens is Senior economist at the Joint Research Centre of the European Commission, E-41092 Seville, Spain. The views and opinions expressed in this paper are the authors' and do not necessarily reflect those of the Joint Research Centre or the European Commission

1 Xuan Pham and Martin Stack, 'How data analytics is transforming agriculture' (2018) 61 Business Horizons, p. 127; Harald Sundmaeker and others, 'Internet of food and farm 2020' in Ovidiu Vermesan and Peter Friess (eds), Digitising the Industry 
based applications and data-driven solutions that are more precise than human observations. ${ }^{2}$ Large amounts of sensor data are used for benchmarking and predictive modelling ${ }^{3}$ to improve and refine decision-making about planting, seeding depth, seed placement, plant disease and machinery diagnostics, tillage, scouting, spraying, ${ }^{4}$ harvesting and even marketing. ${ }^{5}$ Although there are still doubts about the potential benefits compared to the costs, ${ }^{6}$ it is often argued that data-driven services can improve farm productivity ${ }^{7}$ and induce significant changes in the operation, management, and structure of farms and their role in the agricultural supply chain. ${ }^{8}$ Farmers' role as independent decision-makers in the agricultural production process may come under pressure as other parties start contributing to critical decisions and claim a share in the benefits of farm

\footnotetext{
- Internet of Things Connecting the Physical, Digital and Virtual Worlds (River Publishers 2016), pp. 132-133; Sjaak Wolfert and others, 'Big Data in Smart Farming - A review' (2017) 153 Agriculture Systems, pp. 69-75; Michael E. Sykuta, 'Big Data in Agriculture: Property Rights, Privacy and Competition in Ag Data Services' (2016) 19 International Food and Agribusiness Management Review, p. 60; See also Case No COMP/M.8084 - Bayer/Monsanto, Commission Decision (29 May 2018), para. 2442.
}

2 Krijn J. Poppe and others, 'Information and Communication Technology as a Driver for Change in Agri-food Chains' (2013) 12 EuroChoices, pp. 60-63; Krijn Poppe and others, 'A European perspective on the economics of Big Data' (2015) 12 Farm Policy Journal, pp. 11-12.

3 Adam Lesser, 'Analyst Report: Big data and big agriculture' (GIGAOM, 2014) <https://gigaom.com/report/big-data-andbig-agriculture/> accessed 4 March 2021; Wolfert and others, n. 1, p. 73.

$4 \quad$ Keith Coble and others, 'Advancing U.S. Agricultural Competitiveness With Big Data And Agricultural Economic Market Information, Analysis, And Research' (The Council on Food, Agricultural and Resource Economics 2016), p. 3.

$5 \quad$ Wolfert and others, n. 1, p. 74.

6 See, for example, Iria Soto and others, 'The Contribution of Precision Agriculture Technologies to Farm Productivity and the Mitigation of Greenhouse Gas Emissions in the EU' (Joint Research Centre of the European Commission 2019) JRC112505.

7 See 'Internet of Food and Farm 2020' (iof2020eu, 2020) <https:// www.iof2020.eu/communication-materials/iof2020-booklet2019-highres.pdf> accessed 4 March 2021; See also Poppe and others, n. 2, p. 18;

Poppe and others, n. 2, p. 12. operations. In this context, data access and re-use rights will affect competition and may re-distribute welfare between farmers and service providers. ${ }^{9}$

2 The EU is a more active jurisdiction in regulating data issues compared to the US. The primary horizontal legislative instrument in the EU is the General Data Protection Regulation (GDPR). ${ }^{10}$ It assigns exclusive rights over access and use of personal data to natural persons as data subjects and restricts the re-use and re-purposing of these data. We argue in this paper that most agricultural data are non-personal machine/sensor-generated data that do not fall under the purview of the GDPR. ${ }^{11}$ While the data subject is the logical anchor point for inalienable personal data rights, there is no obvious anchor point for rights to non-personal data. Any party that intervenes in the agricultural production process might claim access and use rights over data collected on farms. This unregulated agricultural data market comes close to a free business-tobusiness (B2B) data market, governed only by bilateral contracts between the parties involved. However, competition in that free market is distorted in several ways. Agricultural machines and devices that collect data and implement data-driven services can be designed to give the manufacturer exclusive access to the data. Farmers, who buy these devices in a competitive primary market, are locked into data-driven service providers in aftermarkets. That weakens their bargaining position in aftermarket services. Data lock-in situations also occur when there is no possibility to switch digital services together with historical data sets. ${ }^{12}$ We describe several agricultural business models that build on these data lock-in situations.

9 Data-driven service providers are commonly referred, especially in the US, as Agricultural Technology Providers (ATPs): "The term "agricultural technology provider" or ATP generally refers to a company that aggregates farmer's data, combines it with other relevant data sets, and applies algorithms to analyze the data." See Sykuta, n. 1, p. 58, footnote 1 .

10 Regulation (EU) 2016/679 of the European Parliament and of the Council of 27 April 2016 on the protection of natural persons with regard to the processing of personal data and on the free movement of such data, and repealing Directive 95/46/EC (General Data Protection Regulation), OJ L 119/1, 4.5.2016.

11 Some scholars argue that all data can be linked to a natural person. See, for instance, Nadezhda Purtova, 'The law of everything. Broad concept of personal data and future of EU data protection law' (2018) 10 Law, Innovation and Technology.

12 See Marie-Agnes Jouanjean and others, 'Issues Around Data Governance in the Digital Transformation of Agriculture: The Farmers' Perspective' (OECD 2020), p. 18. 
3 Aftermarket lock-in is a well-known classic problem in competition law and economics. ${ }^{13}$ However, data economics adds additional complications that may further weaken farmers' bargaining position in aftermarkets. Many data applications depend on economies of scale and scope in data aggregation to achieve efficiency gains. This requires a thirdparty intermediary to collect, aggregate and analyse the data of many farms. Individual farmers cannot realise that collective or social value of data. The relatively low market value of raw farm data compared to processed data weakens the bargaining position of farmers in data-driven agricultural services. It explains why farmers pay fees for agronomic services but do not receive payment for their data contributions. The question is whether giving farmers specific non-personal data rights could change that situation.

4 Machine manufacturers and agronomic service providers with exclusive access to data are wellplaced to occupy that intermediary position. Vertical integration with downstream data-driven services reinforces their position. Mergers can create larger data pools and data-driven agricultural conglomerates. ${ }^{14}$ There is a role for competition policy to ensure an appropriate balance between potential efficiency gains from data aggregation and efficiency losses from reduced competition.

5 The lack of clear rules regarding control and access to agricultural data does not seem to satisfy agricultural

13 See, for example, Richard A. Posner, 'The Chicago School of Antitrust Analysis' (1979) 127 University of Pennsylvania Law Review.

14 There has already been a merger trend in the agricultural inputs sector that has also affected the emerging Digital Agriculture sector (DAs). See Case No COMP/M.7962 - ChemChina/Syngenta, Commission Decision (5 April 2017); Case No COMP/M.7932 - Dow/DuPont, Commission Decision (27 March 2017); Bayer/Monsanto, n. 1 above. See discussions in the literature regarding this trend's effects on the DAs in Ioannis Lianos and Dmitry Katalevsky, 'Merger Activity in the Factors of Production Segments of the Food Value Chain: - A Critical Assessment of the Bayer/Monsanto merger' (2017) UCL-CLES Policy Paper Series: 2017/1; Maurice E. Stucke and Allen P. Grunes, 'An Updated Antitrust Review of the BayerMonsanto Merger' (2018) The Konkurrenz Group White Paper; Tom Verdonk, 'Planting the Seeds of Market Power: Digital Agriculture, Farmers' Autonomy, and the Role of Competition Policy' in Leonie Reins (ed), Regulating New Technologies in Uncertain Times (Springer 2019), pp. 112-115. industry stakeholders. In the $\mathrm{EU}^{15}$ and the $\mathrm{US},{ }^{16}$ they have independently created two data charters to fill the perceived regulatory gaps with voluntary rules and principles. ${ }^{17}$ The charters seek to emulate the EU GDPR by assigning a primary data ownership right to farmers. We analyse the impact of the charters on farmers' ability to overcome monopolistic data and aftermarket lock-in problems. We find that, while the EU and US charters differ on a number of points, their legal design limits the potential of the proposed rules and principles. They generally accept the primacy of bilateral free-market contracts over proposed rights for farmers. Aftermarket lock-in, combined with economies of scale and scope in data aggregation, explain why free-market bargaining overrules the data ownership principles in the charters.

6 We then look at two alternative responses to overcome the lock-in problem and facilitate switching between alternative aftermarket service providers: a) the ability of neutral third-party data intermediaries to unlock farmers and b) regulatory intervention with mandatory data portability right and interoperability obligations. We show how neutral data intermediaries that are not vertically integrated with machine or input sales, face problems in collecting sufficient data to realise the value-added from economies of scale and scope in data aggregation and how this weakens the financial sustainability

15 'EU Code of conduct on agricultural data sharing by contractual agreement' (Copa and Cogeca at all, 2018) <EU_Code_of_conduct_on_agricultural_data_sharing_by_contractual_agreement_update_2019.pdf_accessed 4 March 2021.

16 'Privacy and Security Principles for Farm Data' (Fb.org, 2016) $<$ https://www.fb.org/issues/innovation/data-privacy/privacy-and-security-principles-for-farm-data> accessed 4 March 2021.

17 Apart from the US and EU, there are also initiatives in New Zealand and Australia, see respectively 'Farm Data Code of Practice' (Advisory Group, 2016) <https://www.farmdatacode. org.nz/wp-content/uploads/2016/03/Farm-Data-Code-ofPractice-Version-1.1_lowres_singles.pdf $>$ accessed 4 March 2021 and 'Farm Data Code' (NFF, 2020) <https://nff.org.au/ wp-content/uploads/2020/02/Farm_Data_Code_Edition_1_ WEB_FINAL.pdf> accessed 4 March 2021. Also, there is a clear interest in generating data governance rules for the sector. See, for instance, an online tool to let stakeholders generate their own data governance rules 'The Codes of Conduct' (GODAN, 2020) <https://www.godan.info/codes/list> accessed 4 March 2021; See the literature review on existing codes of conduct and calls for agricultural data regulation from the perspectives of various fields from ethics to engineering in Simone van der Burg, Marc-Jeroen Bogaardt and Sjaak Wolfert, 'Ethics of smart farming: Current questions and directions for responsible innovation towards the future' (2019) 90-91 NJAS - Wageningen Journal of Life Sciences, p. 9. 
of their business models. We argue that attributing data rights in the absence of an obvious "anchor" party opens the door to many parties involved in farming claiming access rights, not only farmers. It is unclear who should get access to which data and under which conditions.

7 The remainder of this paper is structured as follows. In Section B, we start with a description of the economic efficiency gains from agricultural data and how these are realised in several types of data-driven agricultural business models by also identifying prominent competition concerns including data lock-ins. Section C discusses the legal status of agricultural data as non-personal machine and sensor-generated data. Section D explores to what extent the EU and the US voluntary codes of conduct offer an effective solution to these aftermarket competition concerns. We focus on i) the attribution of original data rights, ii) the re-use of data and iii) data portability. We conclude that the codes do not really change market outcomes and market failures. Section E first discusses the role of thirdparty intermediary platforms as alternative marketbased arrangements to circumvent monopolistic data lock-ins. We show that they depend on data portability and face problems finding a sustainable business model. Second, we explore the possibility of regulatory intervention to facilitate portability and mandatory access to agricultural data, and discuss the complexity of the attribution of data access rights. Section F concludes.

\section{B. The Economics of Agricultural Data}

8 In the first part of this paper, we take a closer look at the market-driven use of agricultural data to understand the competition concerns that need to be addressed before diving into comparing the voluntary data charters developed in the US and EU. We start from different types of agricultural business models that have emerged in digital agriculture. While some platforms have emerged as independent digital service providers without any links to existing agricultural firms, some major data platforms have developed out of existing agricultural firms, including machine manufacturers and agricultural inputs producers. ${ }^{18}$ We compare the business models of these different types of firms, how they monetise and ensure exclusive control over the data that they collect and how they affect the welfare of farmers. We argue that the business models are confronted with a

18 See, for example, Kenney Martin, Serhan Hiam and Trystram Gilles, 'Digitalization and Platforms in Agriculture: Organizations, Power Asymmetry, and Collective Action Solutions' (2020) ETLA Working Papers 78. choice between cooperation and competition among complementary service providers. We then turn to some economic characteristics of data and discuss how they can contribute to economic efficiency gains in agricultural production. We highlight the aftermarket services lock-in and competition problems that occur in this data-driven setting.

\section{Data-driven Business Models in Agriculture}

9 Data is an input in the production of goods and/or services. They have no value on their own. They become valuable only when they can be used to generate revenue in product and services markets. Since data are non-rival, private monetisation of data requires some degree of excludability in their use. If not, they dissipate into the public domain and lose their private market value - but not necessarily their social value.

10 We identify two main business models to generate private market value through excludability. The first one builds on exclusive access to data in agricultural machines, both for upstream data collection through sensors and downstream product and services implementation through actuators. The second uses proprietary knowledge about the optimal use of inputs to maximise production efficiency: seeds, fertilisers and chemicals in crop production as well as feedstock and animal health products in livestock management. These services are provided through an excludable channel, for instance, through devices. The two models may overlap to some extent and require some degree of collaboration. We can also identify a third category of business models that revolves around smaller firms that are either specialised in data collection and analytics, or in product sales but without integrating the upstream and downstream part in a single business model. This includes, for example, data-driven start-ups that apply artificial intelligence and machine learning to generate better agronomic services. ${ }^{19}$ These pure data analytics firms are not vertically integrated. We come back to this intermediate category when the occasion arises throughout the text.

19 A similar classification of data-driven agricultural firms is proposed previously. The authors distinguish five types of intermediary platforms. See Ibid. 


\section{Agricultural machine producers}

11 Agricultural machines are equipped with digital data sensors and actuators. Sensors collect data on the mechanical movements and navigation position of the machine. Actuators use data inputs to activate mechanical movements and steer the machine. For example, a GPS signal sensor captures the precise location of a machine; actuators steer the machine on the basis of instructions received from a computer programme. This combination enables the collection of field-level data and implementation of agronomic advisory services, for example, for automated seeding, fertilising and chemicals inputs. ${ }^{20}$

12 While the market for agricultural machine sales is highly competitive, the market for data that drive aftermarket services is less so. Agricultural machinery manufacturers can design the machine in such a way that they have exclusive access to sensor data and actuators inputs. Once a farmer buys a particular machine, he is locked into the data channels controlled by the machine manufacturer. The manufacturer may use this monopolistic position in upstream data collection, or in access to the downstream implementation of data-driven agronomic services, to leverage his position in downstream services markets. ${ }^{21}$ The lack of interoperability between data formats and devices from different manufacturers reinforces this monopolistic market structure. Agricultural machine producers and service providers deliberately segment the data standards in order to increase switching costs for farmers, reduce competition in aftermarkets and apply monopolistic pricing in aftermarket services. ${ }^{22}$ This was emphasised by KWS (an agricultural company) in the market investigation of the Bayer/Monsanto case:

"It is difficult to switch from one platform to another, since the industry is not able to agree on one common data protocol (joint data format), therefore there is high incentive for the farmer to decide on only one platform. Even though farmers keep the ownership of provided data and they

20 Athanasios Balafoutis and others, 'Precision Agriculture Technologies Positively Contributing to GHG Emissions Mitigation, Farm Productivity and Economics' (2017) 9 Sustainability; See also a preliminary study in this regard Daan Goense, 'The Accuracy of Farm Machinery for Precision Agriculture: A Case for Fertilizer Application' (1997) 45 Netherlands Journal of Agricultural Science.

21 Mihalis Kritikos, 'Precision agriculture in Europe - Legal, social and ethical considerations' (European Parliamentary Research Service 2017), p. 19. See also 'Data revolution: emerging new data driven business models in the agri-food sector' (EIP-AGRI 2016), p. 14

22 Ibid. can contractually request that their data are returned to them, from the technical point of view, such data are not compatible with another platform and can therefore not be easily transferred to another platform from a practical point of view." ${ }^{3}$

13 According to the "Chicago Critique", ${ }^{24}$ there is no need to intervene in the aftermarket when farmers are rational. They will consider the combined costs and benefits in the primary and aftermarket before deciding on the purchase of a device. If farmers are myopic, however, they may struggle to combine cost and benefits in both markets. Lack of transparency at the time of purchase may be an obstacle to rational decision-making. For instance, with long machine lifetimes and a fast-evolving technology environment, mismatches may occur during the lifetime of the machine that are not predictable at the time of purchase.

14 This monopolistic lock-in position is not absolute. Data plug-ins and add-ons can circumvent the manufacturer's monopoly on mechanical access. For example, Bosch has developed, in collaboration with some partners including Bayer's Xarvio, Syngenta and AGCO, the Nevonex interface that seeks to overcome incompatibility problems between agricultural machines. ${ }^{25}$ It consists of an interface that can take data input from various machines, brands and data formats, and send steering signals to a variety of machines, including retro-fitted mechanical devices on existing machines. ${ }^{26}$ In agricultural machinery, there is the Isobus ISO technical standard initiative. ${ }^{27}$ For example, Xarvio designed a data-driven sprayer that can be mounted on existing mechanical sprayers to give them data steering for precision spraying purposes. ${ }^{28}$ These

23 Bayer/Monsanto, n. 1, para 2842.

24 See Posner, n.13 above.

25 See 'Discover What NEVONEX is All About' (NEVONEX powered by Bosch, 2021) <https://www.nevonex.com/how-it-works/> accessed 4 March 2021.

26 Ibid.

27 The worldwide ISO 11783 (ISOBUS) standard defines the communication between agricultural machinery, tractors and implements, and data transfer between these machines and farm software applications. However, it suffers from "forking" problems that are typical for open standards. This has led to a great number of innovative but proprietary ISOBUS solutions that are not necessarily fully interoperable. See 'ISOBUS - AEF Online' (Aef-online.org, 2020) <https://www.aef-online.org/ the-aef/isobus.html\#/About> accessed 4 March 2021.

28 See 'NEVONEX' (Xarvio.com, 2020) < https://www.xarvio.com/ global/en/partnership/nevonex.html> accessed 4 March 2021. 
add-ons with open technical standards may help to overcome interoperability barriers between machines and data-driven agronomic advisory services. However, there are several limitations to these interoperability solutions. First, the Isobus standard suffers from "forking" into several proprietary versions that are not necessarily fully compatible. Second, interoperability does not ensure the transfer of historical farm data between machines and applications. ${ }^{29}$ Third, it remains to be seen how successful interoperable data formats, such as the Isobus standard, will become in the market. Several economic models explain the ambiguity in incentives for firms to open up access to their exclusive data.

15 Incentives may vary according to firms' market shares. Big manufacturers that benefit from a strong market position may be reluctant to give up their advantages. ${ }^{30}$ Smaller manufacturers or companies that have no entrenched position in the agricultural machine market may prefer an open data standard. Smaller firms stand to gain more from interoperability than large firms with strong market positions. ${ }^{31}$

16 Another economic model that explains the ambiguity of incentives is the "co-opetition" (cooperationcompetition) model..$^{32}$ Machine manufacturers can choose to open access to their machine data and make data formats compatible with common standards. This makes it easier for farmers to switch between agronomic service providers in the aftermarket. It increases competition between aftermarket service providers and decreases prices. That will

29 On the various possibilities regarding farm data lock-ins and the importance of historical data sets, see Can Atik, 'Understanding the Role of Agricultural Data on Market Power in the Emerging Digital Agriculture Sector: A Critical Analysis of the Bayer/Monsanto Decision' in Michal Gal and David Bosco (eds), Challenges to Assumptions in Competition Law (Edward Elgar 2021), pp. 56-63.

30 Machine producers ensure their exclusive control of machinegenerated data. For instance, John Deere, a major player in the agricultural machines market, applies end-user license agreements (EULA) that let it block a tractor if the data collection procedure is violated. See 'Vendor lock-in, DRM, and crappy EULAs are turning America's independent farmers into tenant farmers' (boingboing.net, 2018) <https://boingboing.net/2018/03/08/you-are-the-product-5.html> accessed 4 March 2021.

31 Jacques Crémer, Patrick Rey and Jean Tirole, 'Connectivity in the Commercial Internet' (2003) 48 The Journal of Industrial Economics.

32 See Adam M. Brandenburger and Barry J. Nalebuff, CoOpetition (Doubleday 1998) as the standard work on this subject. make the machines more attractive to farmers and increase the market share of manufacturers who sell interoperable machines in the primary machine market. On the other hand, it may decrease aftersales revenue for manufacturers who are vertically integrated into aftermarket services. The net effect of all these factors is a complex empirical question that is hard to predict.

\section{Agricultural input producers}

17 Large input producers have accumulated considerable knowledge in the use of inputs such as seeds, fertilisers, pesticides and other chemicals. Working closely with agricultural extension services, agronomic laboratories and big historical datasets, they have proprietary knowledge about the precise genetic composition and characteristics of seeds, and the biochemical interaction with chemical inputs, soil quality and weather factors. ${ }^{33}$ Besides these large vertically integrated input providers, there are also smaller start-ups that are specialised in data-driven agricultural services only. They both require complementary data to generate tailormade agronomic solutions. An individual farmer's experience and data cannot match the insights obtained from large data pools and economies of scale and scope in the analysis of these fine-grained farm-specific data about actual input use and crop yields. Some data can be obtained from the market, and some need specific contractual relationships. For instance, coarse-grained land maps can be obtained from free satellite services (scale 10x10 meters) while more fine-grained mapping (up to $30 \times 30 \mathrm{~cm}$ ) is available for a price. ${ }^{34}$ Farm specific data, such as detailed irrigation and soil data, need to be collected from the target farm. Combined with detailed weather forecasts, they enable the production of very granulated agronomic advisory services tailored to the needs of individual farmers and fields. ${ }^{35}$ Service providers store historical data collected from farms. They have exclusive de facto control over these farm-specific data sets. ${ }^{36} \mathrm{New}$

33 See Bayer/Monsanto, n. 1, paras 2453-2455 and 2715-2724.

34 Many firms are producing and selling land images based on satellite and drone pictures. For an overview of pricing according to scale, see for example, 'Buy Satellite and Drone Imagery | Our Imagery Pricing Plans' (Geocento.com, 2020) $<$ https://geocento.com/imagery-pricing-plans/> accessed 4 March 2021.

35 See more about generating data-driven agronomic services/ prescriptions/solutions for farmers in Wolfert and others, $\mathrm{n}$. 1 above.

36 See this cross dependency of farmers and ATPs in Atik, n. 29, 
market entrants will need to access these historical data to generate accurate prescriptions ${ }^{37}$ when farmers desire to change service providers. This creates a data lock-in situation for farmers, which can jeopardise competition in the emerging markets of data-driven agronomic services. ${ }^{38}$ Vertically integrated agronomic advisory services can be combined with agricultural inputs sales. This entails the risk of self-preferencing: the service provider can recommend its own upstream products even though they are not objectively the best or cheapest product to suggest. Self-preferencing may reduce competition in upstream inputs markets.

18 Integrated input producers can monetise their information advantage in the form of agronomic services. They can simply send the advice to the farmer and enable him to implement it manually on these fields. For instance, advice can be dispensed through apps on mobile devices. Combined with field navigation maps, the farmer can steer his machines as required. Alternatively, advisory services can be dispensed automatically by proprietary data interface devices that directly steer machines. Many companies have developed such interfaces. Monsanto's subsidiary, the Climate Corporation, has introduced FieldView, a service that makes agronomic advice available to farmers and interacts with agricultural machines. ${ }^{39}$ Bayer generated a similar service called FieldManager. ${ }^{40}$ BASF uses the Maglis interface ${ }^{41}$ and DowDuPont has various digital products that are sold in the US through its

pp. 64-68

37 Based on retroactive patterns. See Keith H. Coble and others, 'Big Data in Agriculture: A Challenge for the Future' (2018) 40 Applied Economic Perspectives and Policy, pp. 87 and 91.

38 See Atik, n. 29, pp. 56-73.

39 See 'Digital Farming Decisions and Insights to Maximize Every Acre' (Climate.com, 2020) <https://climate.com/> accessed 4 March 2021.

40 It is now controlled by BASF in the scope of the remedy package of the Bayer/Monsanto decision. See "The BASF Divestment Package" in Bayer/Monsanto, n. 1, para 3069 and subsequent paras. See the current services of FieldManager at 'FIELD MANAGER' (Xarvio.com) <https://www.xarvio.com/nl/nl/ FIELD-MANAGER.html> accessed 4 March 2021.

41 "BASF Launches Maglis, a New Online Platform to Help Farmers Improve Crop Management" (BASF) < https:// www.basf.com/en/company/news-and-media/newsreleases/2016/03/p-16-140.html> accessed 4 March 2021. subsidiaries Pioneer ${ }^{42}$ and Corteva Agriscience. ${ }^{43}$ These companies can negotiate agreements with machine manufacturers to create a direct data access gate. For example, in the US, agricultural machine manufacturer John Deere came to an agreement with the Climate Company to let machines from the former interact with advisory services from the latter. $^{44}$

19 Proprietary devices that dispense agronomic services can be used to leverage these integrated giants' positions in the markets for data-driven agronomic services or inputs sales. Once farmers buy into a device that has special arrangements with a particular agronomic service provider, they are locked into the device and the agronomic aftermarket service, especially when it uses noncompatible and non-interoperable data formats and software design. This aftermarket lock-in enables firms to charge a monopolistic price for their advisory services and inputs sales. Firms can either choose a lock-in strategy to avoid farmers' switching between data platforms, or choose an open system strategy to attract more farmers. Another strategy to circumvent exclusive cooperation between machine manufacturers and service providers is the use of machine add-ons that by-pass the manufacturers' exclusive data channels. The above example from Nevonex illustrates the latter case.

20 Agronomic service providers face the same trade-off between competition and cooperation as machine manufacturers. They can perceive machines as complementary products because their customers may value agronomic services more when combined with the manufacturer's machine compared to having the service alone. They may also perceive

42 'Farm Management Software' (Pioneer.com, 2021) <https:// www.pioneer.com/us/tools-services/granular.html> accessed 4 March 2021.

43 'Software and Digital Services' (Corteva.us, 2021) <https://www. corteva.us/products-and-solutions/software-and-digitalsolutions.html> accessed 4 March 2021.

44 'John Deere and the Climate Corporation Expand Precision and Digital Agriculture Options for Farmers' (Climate.com, 2015) $<$ https://climate.com/newsroom/john-deere-climate-corpexpand-precision-digital-ag-options/15> accessed 4 March 2021. However, this agreement was investigated by the US District Court of Illinois from the perspective of antitrust concerns. See US District Court of Illinois, case 1:16-cv-08515, the US Justice Department as plaintiff against Deer \& Company and Precision Planting as defendants. Eventually, the parties cancelled this agreement. See 'Monsanto Terminates Agreement for Sale of Precision Planting Equipment Business' (Climate.com, 2017) <https://climate.com/newsroom/ monsanto-terminates-agreement-for-sale-of-precisionplanting-equipment-business/25> accessed 4 March 2021. 
them as competitors if customers will pay less for the agronomic services when combined with the machine than when they buy the services separately. This is again a hard empirical question.

\section{Complementary nature of business models}

21 The machine-centred and the agronomic servicescentred data-driven business models are complements, and there is some degree of convergence between the two. Machine manufacturers can either produce their own complementary agronomic advisory services or, alternatively, negotiate an agreement with other agronomic service providers to share these data channels for the purpose of dispensing agronomic services. The tension between competition and cooperation is always present. In line with the co-opetition model, ${ }^{45}$ machine manufacturers seek collaboration agreements with inputs and advisory service providers, and vice versa. For example, John Deere, an agricultural machinery manufacturer, focuses on machine-based data collection while Bayer and Monsanto, agricultural input providers, focus on data-driven agronomic services in input markets. ${ }^{46}$ There are many collaboration agreements between these companies. Monsanto (or Bayer, now), for example, has agreements with machine manufacturers John Deere, Agco and CNHI, through its subsidiary, the Climate Corporation, which specialises in data-driven agronomic services. ${ }^{47}$ These collaboration agreements fall short of mergers, but they nevertheless involve coordination.

\section{Economies of Scale and Scope in Data Aggregation and Re-use}

22 In the previous section, we examined two private business models that seek to monetise the value of agricultural data through data lock-in, either by linking primary machine markets with aftermarket services or linking data-driven agronomic services with inputs markets. These lock-in situations are well-known in classic competition policy. In this section, we focus on the underlying sources of agricultural efficiency or productivity gains from digital data. This creates new competition problems in data markets, with spill-over effects to machine and agronomic services markets.

\footnotetext{
45 Brandenburger and Nalebuff, n. 32 above.

46 Bayer/Monsanto, n. 1, paras. 2774-2775.

47 Ibid., para. 2815.
}

\section{Economies of scale in data aggregation}

23 Statistical analysis requires large samples of data in order to extract insights. Economies of scale occur when adding more observations on the same variables in a sample increases the accuracy of the statistical predictions. For example, more observations on the response of crop yield to different types of fertiliser improve the prediction accuracy for fertiliser. More fine-grained soil maps allow for more precise application of fertiliser and chemicals in fields. ${ }^{48}$ These improvements will, at some point, become subject to diminishing returns to scale or the number of observations.

24 Economies of scale constitute an argument in favour of data concentration in large databases, allowing firms to accumulate and combine data from many sources.

\section{Economies of scope in the re-use of data}

25 Contrary to ordinary goods that are rival and can only be used for one purpose at the time, data are non-rival. Many parties can use the same dataset at the same time for a variety of purposes. Economic efficiency gains occur when data collected by a firm can be re-used for other purposes. Economies of scope in re-use ${ }^{49}$ can be realised either by the firm that collected the data and re-uses it in-house for other purposes or by sharing/selling the data to another firm that uses it for another purpose. For example, a tractor is a rival physical good and can only be used by one farmer at the time. If a tractor would be non-rival, all farmers could use the same tractor at the same time to work in different fields. The welfare gains would be enormous: it would suffice to invest in the production of a single tractor to cater to the needs of all farmers. This prospect can be achieved with data. For example,

48 Another example is the prevention of the spread of plant diseases. The aggregation of fragmented data sets from different farms can help to prevent that spreading and reduce costs for the economy. See Martin Parr, 'Who Owns Open Agricultural Data? - The Plantwise Blog' (The Plantwise Blog, 2015) <https://blog.plantwise.org/2015/12/04/who-ownsopen-agricultural-data/> accessed 4 March 2021.

49 For a more detailed explanation of economies of scope in re-use of products in general, see John C. Panzar and Robert D. Willig, 'Economies of Scope' (1981) 71(2) The American Economic Review; David J. Teece, 'Economies of scope and the scope of the enterprise' (1980) 1(3) Journal of Economic Behaviour \& Organisation; David J. Teece, 'Towards an economic theory of the multi-product firm' (1982) 3(1) Journal of Economic Behaviour and Organisation. 
detailed farmland and soil survey maps can be used for precision farming applications for all types of inputs and services on that farm - but not on other farms. Collecting the data comes at a fixed cost. Reuse of the same non-rival data for another purpose entails quasi-zero marginal reproduction costs of an electronic data file. Economies of scope in re-use constitutes an argument in favour of wider access to data. Many applications of data in farming are reuse applications. Farmers share land and soil map data with agronomic services, or livestock health and production data with service providers.

26 Contrary to economies of scale, economies of scope in the re-use of data constitute an argument in favour of de-concentration of data, facilitating the distribution of data over many applications and allowing access by many firms for competing applications.

27 Data access may also come at a cost. Privacy and commercial confidentiality are important for the autonomy of private decision-making by firms and individuals and for extracting private value from these decisions. ${ }^{50}$ When data are used by a competing firm to produce a substitute good or service, it may harm the interests of the original data collector. When data become widely available, it erodes the market value of the data for the original collector and may become a disincentive for continued investments for data collection.

28 An ideal data governance regime would thus seek an optimal combination of wider access and exclusive control, a balance between anti-competitive concentration and competitive decentralisation..$^{51}$ Data are not excludable by nature. They require technical and/or legal protection to ensure exclusive access for one party. That is what machine manufacturers and agronomic advisory services aim to achieve by channelling data-driven services through exclusively controlled devices.

\section{Economies of scope in data aggregation}

29 When two datasets are complementary, more insights and economic value can be extracted from

50 See John G. Palfrey and Urs Gasser, Interop: The Promise and Perils of Highly Interconnected Systems (Basic Books 2012).

51 This balance between competitive and anti-competitive forces has become a major issue in recent policy debates on anti-competitive behaviour by all kinds of digital data platforms. See for example Luis Cabral and others, 'The EU Digital Markets Act A Report from a Panel of Economic Experts' (Joint Research Centre of the European Commission 2021) - JRC122910. the analysis of the merged dataset, compared to applying data analysis to each of the separate data sets. ${ }^{52}$ Economies of scope in data aggregation constitute another argument in favour of large data pools and concentration of data. They are a critical factor in the success of digital farming.

30 At the same time they trigger concerns from competition authorities, as shown by the market investigation of the European Commission's Bayer/ Monsanto merger decision:

\begin{abstract}
"The more data (and the more specific data) you have, the more robust your algorithms will be and the more proven results you will have as references to your potential customers. (..) Covering more crop varieties, more climate areas, more soil types, etc allows you to expand your offering to other areas and cultures and because it is a complex system that constantly evolves, it is important to have different independent and broadly representative sources of information to build the necessary expertise." ${ }^{3}$
\end{abstract}

31 The merger between Bayer, a chemicals producer, and Monsanto, mostly known for genetically modified seeds, was designed to generate more benefits from their combined agronomic research, including in the digital era where big data collection and the use of artificial intelligence to comb through these datasets would have become primary tools to advance research. The merger decision package sought to reduce economies of scale and scope in data aggregation in order to maintain competition..$^{54}$

32 Economies of scale and scope are two distinct measures. In our fertiliser example, economies of scale are related to the number of observations on a particular fertiliser. Economies of scope occur when more variables are added to estimate the impact of fertilisers on yields, such as soil and weather conditions and the use of different chemicals.

52 Economies of scope in aggregation goes back to insights from the economics of learning. See Sherwin Rosen, 'Specialization and Human Capital' (1983) 1(1) Journal of Labor Economics. Rosen observed that when a person has a choice between learning two skills, specialisation in one skill is always beneficial when the costs of learning both skills are entirely separable. However, when learning costs are not separable and learning one skill decreases the cost of learning another, then there are economies of scope in learning both skills, provided that the benefits from interaction exceed the additional learning costs.

53 Bayer/Monsanto, n. 1, para. 2726.

54 The BASF divestment package, as the main remedial condition of the decision, aimed to keep the merging parties' Digital Agriculture operations and data sets separate. See more details in Ibid., para. 3046 and subsequent paras. 
33 Realising economies of scale and scope in data aggregation requires "big" datasets, usually across many farms, inputs, outputs and production conditions. Individual farmers cannot realise these benefits. It requires a third-party intermediary who collects and aggregates data from many sources in order to extract more insights from the pooled data compared to the insights that farmers could extract from their own datasets. ${ }^{55}$

34 Intermediaries are not necessarily large firms. Small start-up firms may be able to collect a sufficiently large data sample and reach a high level of economies of scale and scope in selected data domains. However, specialisation in one specific area is not sufficient to be competitive in a wide range of agronomic services markets that span many complementary and substitute products and crops. ${ }^{56}$

35 An important consequence of economies of scale and scope in aggregation is that the collective or social value of farm data is usually higher than the private value of data for individual farmers..$^{57}$

36 The existence of a gap between private and social value implies an inherent market failure. Purely private data ownership rights may therefore not be an optimal allocation mechanism. Neither is purely public and common access to data because that would eliminate any market value for data. All benefits would be dissipated as user surplus and would dis-incentivise investment in data collection. This constitutes an argument in favour of regulatory intervention to overcome data market failures and put in place alternative data access regimes that seek to realize the social value of data while preserving competition in data-driven services markets.

37 Another source of market failure occurs when data aggregation generates negative externalities for farmers. Economies of scale and scope in data aggregation are subject to diminishing returns. ${ }^{58}$

55 For more details on the role that data platforms play in realising the social value of data, see Bertin Martens, 'Data Access, Consumer Interests and Social Welfare: An Economic Perspective' (2020) <https://ssrn.com/abstract=3605383> accessed 4 March 2021.

Bayer/Monsanto, n. 1, paras. 2758-2762.

57 Dirk Bergemann, Alessandro Bonatti and Tan Gan, 'The Economics of Social Data' (2020) Cowles Foundation Discussion Paper - N. 2203R.

Economies of scale and scope in data aggregation are easily confused with network effects. We do not think this terminology is appropriate in the case of agricultural data. Social media users, for example, are attracted by network effects because they want to be able to contact many other users. By
Once an agricultural service provider has collected a dataset that is sufficiently large to produce algorithms with a high level of prediction accuracy, the marginal value of collecting additional data from farms is low or zero. This depresses the market value of individual farm data ${ }^{59}$ and puts farmers in a weak bargaining position with regard to their data. Even if they did not face data portability or interoperability obstacles, they would not be in a position to monetise the value of their data. Conversely, it explains to a certain extent why intermediary platforms cannot give farmers a meaningful remuneration for their data. They can only ensure their financial sustainability by charging for the data-driven services that they offer. ${ }^{60}$

38 Several digital economy studies ${ }^{61}$ already highlighted how the data-driven platform economy is torn between efficiency and welfare gains from data aggregation in intermediary platforms and anticompetitive behaviour by these monopolistic data giants.

\section{The Legal Status of Agricultural Data}

39 In the Bayer/Monsanto decision, the Commission classifies agricultural data in three types: (i) farm data collected from fields or barns via sensors in machines or provided by farmers, (ii) complementary data from specialised providers outside the farm (such as land and soil maps, weather, satellite and other environmental data), and (iii) proprietary data from agricultural inputs producers and data analytics service providers. ${ }^{62}$

contrast, farmers are not necessarily interested in contacting each other. They are interested in getting more efficient services. See similar considerations in Atik, n. 29, pp. 72-73. That requires data aggregation across many farms, products and circumstances, up to the point where diminishing returns to scale and scope in data aggregation set in.

59 For an application to personal data, see Daron Acemoglu and others, 'Too Much Data: Prices and Inefficiencies in Data Markets' (2019) NBER Working Paper - N. 26296.

60 See the discussion on the prominent business model in the emerging Digital Agriculture sector and cross dependency of farmers and service providers in Atik, n. 29, pp. 65-68.

61 See Cabral and others, n. 51. More explanations are provided in Bertin Martens 'An economic perspective on data and platform market power' (Joint Research Centre of the European Commission 2021) - JRC122896.

62 See Bayer/Monsanto, n. 1, para 2453 and subsequent paras. 
All three categories are mostly machine-generated, either as raw data or as the outcome of data processing.

40 To identify their legal status, the first question is whether they can be considered as personal data within the scope of the GDPR. Article 4 of the GDPR defines personal data as "any information relating to an identified or identifiable natural person ('data subject')...". The GDPR gives the data subject a number of rights to the data collected by a service provider or hardware manufacturer, including the right to consent for collecting the data or re-using them for other purposes; the right to access and delete personal data; and to retrieve or transfer (portability) data. ${ }^{63}$ As such, the GDPR automatically links personal data collected by a device to the data subject, irrespective of device ownership. Device owners, renters and operators, or service performers using the device as an intermediary, always require the consent of the data subject before they can collect personal data. The data subject retains inalienable non-tradable rights to the collected personal data. He can share data with other parties, but fundamental rights to the data will always remain attributed to the data subject, unless the data are anonymised in such a way that the link between the data and the data subject is irreversibly broken.

41 There are several legal reasons to consider agricultural machine-generated data outside the scope of the EU GDPR. Kritikos is very prudent in this regard as he states that "not all categories of data involved in precision agriculture such as agronomic data, compliance data and meteorological data, actually qualify as personal data..." apart from explicitly identified ${ }^{64}$ or easily identifiable ${ }^{65}$ data that are already under the protection of GDPR framework. ${ }^{66}$ We argue that it is usually not possible to link machine/sensorgenerated farm data with an identified or identifiable

63 For a discussion on the limitations of the data portability right under the GDPR from the competition perspective, see Inge Graef, Martin Husovec and Nadezhda Purtova, 'Data Portability and Data Control: Lessons for an Emerging Concept in EU Law' (2018) 19(6) German Law Journal. See also Jan Krämer, Pierre Senellart and Alexandre de Streel, 'Making Data Portability More Effective for The Digital Economy: Economic Implications and Regulatory Challenges' (Centre on Regulation in Europe 2020).

64 such as "financial/economic data and staff data or other data derived from people's behaviour" see Kritikos, n. 21 above, p. 14-15.

65 such as drone images which cover humans. Ibid.

66 OECD working paper also considered agricultural data sets are mostly outside the scope of the GDPR framework. See Jouanjean and others, n. 12 above, pp. 10-11. natural person as most data are directly collected from fields, greenhouses or barns via IoT technology. They provide information about, for instance, machines, soil, plants, products and animals, not about the state or the behaviour of natural persons. Similarly, other components of agricultural data, i.e. complementary data and proprietary data sets, are not related to an identified or identifiable natural person. They are about environmental conditions or performances of agricultural inputs such as seeds or pesticides. Any human identification data that might be collected besides machine data has no relevance for the purpose of farm decision making. The identity of the human farm worker, even if known, is usually not relevant for the purpose of agricultural services. Human intervention in data collection does not necessarily change the legal status of farm data. The applicability of the GDPR in farms is limited because only natural persons can be beneficiaries of the GDPR. ${ }^{67}$ So, farms as legal entities cannot institutionally benefit from the GDPR. ${ }^{68}$

42 A number of EU documents confirm the classification of precision farming data as non-personal data. The Commission defines machine-generated data as "created without the direct intervention of a human ... by sensors processing information received from equipment, software or machinery, whether virtual or real", ${ }^{69}$ and cites agricultural data as an example. ${ }^{70}$ Recital 9 of the Regulation on the Free Flow of Non-Personal Data confirms that it applies to agriculture: “... Specific examples of non-personal data include ... data on precision farming that can help to monitor and optimise the use of pesticides and water." Unlike the GDPR, this regulation does not define rights for non-personal

67 See Article 1 of the GDPR, n. 10 above.

68 See more in Atik, n. 29, pp. 57-58.

69 See the Communication from the Commission 'Building a European Data Economy’ COM(2017) 9 final, p. 9.

70 "In general, data can be personal or non-personal. For example, data generated by home temperature sensors may be personal in nature if it can be related to a living person, while data on soil humidity is not personal. ... Where data qualifies as personal data, the data protection framework, in particular the GDPR, will apply." Emphasis added. Ibid. The Commission has a similar understanding for IoT data. See, for instance, "non-personal data generated by Internet of Things objects in an automated manner." Emphasis added. See the Communication from the Commission "Towards a common European data space' COM(2018) 232 final.

71 See Regulation (EU) 2018/1807 of the European Parliament and of the Council of 14 November 2018 on a framework for the free flow of non-personal data in the European Union, OJ L 303, 28.11.2018. 
data. ${ }^{72}$ It is only a general framework for sectoral codes of conduct and possible future regulatory interventions. ${ }^{73}$ There is no binding data portability provision for non-personal data sets.

43 Portability is only possible when standard terms and conditions let farmers do so. However, practice is not in favour of farmers. ${ }^{74}$ For example, the FieldView farmer interface, produced by the Climate Corporation, restricts the definition of personal data to name, address and other personal details of the farmer. ${ }^{75}$ Although the farmer is confirmed as the owner of all non-personal data, portability is limited to other FieldView users or platform partners only. This is further restricted because hardware and software that store the data are licensed, not sold. That includes the FieldView Drive, the hard disk that collects and stores all data. Data are accessible anytime, but the hardware should be returned at the end of the contract. ${ }^{76}$ In this environment, there is no way for farmers to transfer their (historical) data to another platform. It locks them in the existing service provider or machine producer.

44 We conclude that most agricultural data are nonpersonal and fall outside the scope of the EU GDPR and its right to data portability. For non-personal data, there is no de jure allocation of legal rights, neither in the EU nor in the US. Also, there is no undisputed ex-ante legal framework that can unchain farmers from the data lock-ins. ${ }^{77}$

72 Article 1 of the Regulation (EU) 2018/1807 "aims to ensure the free flow of data other than personal data within the Union by laying down rules relating to data localisation requirements, the availability of data to competent authorities and the porting of data for professional users."

73 See Ibid., Article 6. However, as we discuss in detail at section D below, existing voluntary codes have significant limitations in their design to achieve the policy goal of enhancing free flow of non-personal data not only in the EU, both also in other jurisdictions such as the US, New Zealand and Australia.

Kritikos, n. 21, p. 17; Jop Esmeijer and others, 'Data-driven innovation in agriculture: Case study for the OECD KBC2-programme' (TNO 2015) - R10154, p. 27; See also Matt McIntosh, 'Data Ownership Questions - and Why They're Important' (Future Farming, 2018) <https://www.futurefarming.com/ Tools-data/Articles/2018/10/Data-ownership-questions-and-why-theyre-important-340743E/> accessed 4 March 2021.

75 'Climate Fieldview ${ }^{\mathrm{TM}}$ Terms of Service' (Climate.com, 2020) <https://climate.com/fieldview-terms-of-service> accessed 4 March 2021.

The Directorate General for Communications Networks, Con-
45 In this almost regulation-free data environment, ${ }^{78}$ stakeholders can negotiate claims to data in bilateral contracts to determine access and use rights to the data. Market forces and bargaining power will determine the outcome. Technology may also play a role because device manufacturers and agricultural technology providers can design the data collection and storage processes in such a way to ensure their de facto exclusive access to the data.

\section{The US and EU Agricultural Data Charters}

46 The absence of a clear legal framework for nonpersonal agricultural data has been perceived as a shortcoming and motivated agricultural stakeholders in the US and EU to draft voluntary data rules. ${ }^{79}$ They are not legally enforceable but are meant to be guiding principles in data transactions. The US Privacy and Security Principles for Farm Data (the US Principles, henceforth) were signed by a number of companies and organisations on April 1, 2016.80 It covers ownership, transparency, portability, collection, access and control. The signatories formed the Ag Data Transparency Evaluator Inc. that audits companies' ag-data contracts and issues the Ag Data Transparency Seal, a certificate of conformity with the principles for data-collecting agri-tech companies. ${ }^{81}$ Two years later, the EU Code

tent and Technology of the European Commission released a report that investigates the EU acquis that is potentially applicable to sharing of non-personal data. See "Analytical Report on EU Law Applicable to Sharing of Non-Personal Data' (DG CONNECT 2020). However, there is no mechanism equivalent to a portability right.

78 See a detailed discussion of recent EU proposals to regulate data and digital markets in Section $\mathrm{E}$ below.

79 in addition to other voluntary attempts in other jurisdictions such as in Australia and New Zealand.

80 See $n .16$ above.

81 'About - Ag Data Transparent' (Ag Data Transparent) <https:// www.agdatatransparent.com/about> accessed 4 March 2021. This might be a factor that compensates the voluntary nature of the rules to a certain extent because, at least, this might be a mechanism to track whether companies abide by the proposed principles or not. The limitation of this seal is also related to the contractual superiority design in the US principles. As the US rules keep a significant leeway to deviate from the principles with contractual agreements, blocking portability by a company might not be incompliant with the principles per se, and thus, seal requirements. In sum, the general limitation of the contractual superiority approach in the Principles also blocks the potential of this verification 
of Conduct on agricultural data sharing (the EU Code, henceforth) was released by a coalition of EU agrifood associations on 23 April 2018 in Brussels. ${ }^{82}$ The EU Code is a more comprehensive report with not only definitions of rules but also case examples.

47 Both the EU and US data charters take inspiration from the EU GDPR and seek to introduce GDPRlike data rights for farmers such as consent, access, portability, purpose and re-sale limitations. They are farmer-centric in the sense that they try to establish a direct link between data rights and the operator of the farm - although the EU Code is a bit ambiguous on this aspect. They aim to portray the farmer as the equivalent of the "natural person" in the GDPR. Unlike the GDPR that assigns certain inalienable rights to natural persons, both data charters introduce tradable data ownership and alienable data rights. We compare both data charters in this section. In particular, we inquire to what extent they are able to overcome the lock-in and foreclosure data market failures identified above.

\section{Attribution of Original Data Rights - Ownership Rights}

48 The US document distinguishes between farmers and service providers (called Agriculture Technology Providers or ATPs), and attributes original rights (ownership of data) to farmers:

\footnotetext{
"Farmers own information generated on their farming operations. However, it is the responsibility of the farmer to agree upon data use and sharing with the other stakeholders with an economic interest, such as the tenant, landowner, cooperative, owner of the precision agriculture system hardware, and/or ATP etc. The farmer contracting with the ATP is responsible for ensuring that only the data they own or have permission to use is included in the account with the ATP."
}

49 The US text unambiguously attributes the "ownership of data' to farmers ${ }^{83}$ who generate data on their farming operations. Data ownership ${ }^{84}$ is divorced

of compliance design to a large extent.

82 See n. 15 above.

83 Note the ambiguity of the use of the word "farmer". It may refer to the farm as a legal entity but also to a natural person who is in charge of the farming operations. The former interpretation might have been intended here in order to reinforce the similarity with personal data rights.

84 There is some research on data ownership in agricultural data. See the literature review by van der Burg, Bogaardt and Wolfert, n. 17, pp. 3-5. from machine, device or land ownership, including from external parties that perform services on the farm. Ownership is attributed to the party that decides and manages the farming operations. The data are not considered as the product of device ownership, but rather of the farming operation: farmers' efforts and practices. The text makes farmers responsible for any data sharing with other stakeholders with an economic interest by means of contracts, but this responsibility is ambiguous. There is no clarification in the text that implies rights for stakeholders or any mechanism to be used by them to access the data. This looks more like an advisory statement for farmers. The text uses ownership as the central legal concept when designing data rights. However, ownership rights are tradable/alienable. Although some parts of the text seem to provide inalienable consent rights to data re-use (see section 3.2. below), the data ownership design behind the US Principles limits the potential of the proposed rights with their alienable/transferable nature.

50 The EU Code has a more ambiguous wording. It distinguishes between data originators, providers and users. ${ }^{85}$ It attributes data ownership rights to data generated during farming operations to data originators, i.e. the right to benefit from and/or be compensated for the use of data created as part of their activity. However, when data are produced by a service provider or external operator on the farm in the course of their activity, the operator might be considered as the data originator, not the farmer:

The originator (owner) - "the person or entity that can claim the exclusive right to licence access to the data and control its downstream use or re-use"s6

"The data originator of all the data generated during the operation is the one who has created/collected this data either by technical means (e.g. agricultural machinery, electronic data processing programs), by themselves or who has commissioned data providers for this purpose." ${ }^{" 77}$

"This Code recognises the data originator's right, whether they are a farmer or another party..." 88

51 Clearly, the data originator may be different from the farmer, especially in automated data collection.

85 See the EU Code, n. 15, pp. 5-9.

86 Ibid., p. 6.

87 Ibid.

$88 \quad$ Ibid., p. 8. 
It is not clear whether the operator would be the owner of the device, the device controller, or possibly the farmer who may have rented a device. Data collection may be conducted by a third party, commissioned by the farmer and with the aim to facilitate farmers' decision-making. If data-collecting sensors in machines are not owned by farmers, the sensor/machine owners are the data providers, not the data originators:

"It can be assumed that the data originators are the farmers, also from data of sensors that are owned by the farmer. If sensors are not owned by the farmers, the sensor owners are seen as data providers." ${ }^{\circ 9}$

52 The notion of data provider refers to a natural or legal person who, under an agreement, delivers data to the data user and/or data originator..$^{90}$ Although these extra definitions (data user and data provider) create confusion regarding the attribution of original rights, the owner is data originator.

53 An additional provision in the Code adds to the confusion because it seemingly reverses the provision that data rights can be owned by other parties than the farmer:

"Rights regarding data produced on the farm or during farming operations are owned by the farmer and may be used extensively by them." ${ }^{\prime \prime}$

54 The attribution of original rights emphasises data on "the farm or during farming operations". This may be interpreted as indicating raw farm data only, not processed data. The text may be intentionally silent on processed data, leaving it out of the data charter and subject to the free market.

55 Both data charters have repetitive statements that indicate that related rights can be alienable and transferable, i.e. they can be traded through bilateral contracts. This is compatible with the concept of ownership. Bilateral negotiations imply that bargaining power will play an important role in deciding who ends up with the effective ownership right of the data. For example, powerful data aggregators who can extract more value from large data pools could end up acquiring the data. This may be beneficial for farmers if it allows them to obtain the highest value for their data. It may also be detrimental when farmers are locked-in machine data and data-driven services markets are foreclosed. For example, machine manufacturers or service providers may have exclusive control over access

\footnotetext{
89 Ibid., p. 15

$90 \quad$ Ibid., p. 7.

91 Ibid., p. 8.
}

to the data that enables them to foreclose the market for downstream use of the data for the purpose of agricultural services. That leaves no other option to the farmer than to accept the proposed terms and conditions that may contain provisions to transfer ownership rights from farmers to machine producers or technology providers. Portability rights would open the door to circumvent lock-in situations, but it is unlikely to be enforced together with the alienable and exclusive data ownership understanding.

56 Despite the fact that the EU and US agricultural data charters were inspired by the GDPR, ${ }^{92}$ the introduction of tradable data ownership rights shows how the charters represent a clear departure from the underlying principles of the GDPR, where rights to personal data are considered as fundamental and inalienable human rights. ${ }^{93}$ Even if the data rights are allocated initially to the farmers, bargaining power determines which party eventually ends up with the rights to use the data. Consequently, data ownership as conceived in both the EU and US charters is not able to address lock-in concerns and broader data access problems in the sector. Inalienability might protect farmers from powerful service providers or machine producers in terms of controlling collected raw farm data in a sustainable way. ${ }^{94}$ Also, inalienable data rights do not necessarily exclude other stakeholders from using the data. For instance, while farmers can have rights to data portability when changing services, the same data can also be used for training algorithms by the previous technology provider, or the new tenant of a rented farm field might benefit from the historical data sets.

57 However, since farms are tradable assets, all the rights that they acquire should be by definition tradable as well. So, inalienable rights should stay with the farm, not with the farmer as an individual. Otherwise, it may create problems when farms are sold while rights remain with the farmer. Inalienable

92 As it can be seen from the following part of this section, they both used GDPR concepts, but sometimes this transplantation approach does not match the non-personal agricultural data.

93 With regards to the Australian and New Zealand ag-data codes, it has to be noted that they do not mention ownership of farm data as they solely revolve around particular principles such as data security, data access and retention. In this regard, it has to be stated that they adopt a less problematic approach when designing their texts.

94 See the previous arguments in this regard at Can Atik, 'Data Ownership and Data Portability in the Digital Agriculture Sector: A Proposal to Address Novel Challenges' (Florence School of Regulation, 2019) <https://fsr.eui.eu/atik-c-how-big-dataaffects-competition-law-analysis-in-online-platforms-andagriculture-does-one-size-fit-all/> accessed 4 March 2021. 
rights for farms not only protect the farmer while he owns the farm, but also allow him to sell the rights together with the farm. Alienable rights imply that the rights to data can be sold separately from rights to the legal entity of the farm. Big data firms might hoover up farm data rights without owning farms. That would handicap future owners of farms and diminish the value of farms.

\section{Data re-use, Access and Consent Rights}

58 Under the title "Collection, Access and Control" the US Principles state that;

\begin{abstract}
"An ATP's collection, access and use of farm data should be granted only with the affirmative and explicit consent of the farmer. This will be by contract agreements, whether signed or digital."
\end{abstract}

59 This gives farmers an exclusive decision right over data access and re-use by third parties, as an attribute of their data ownership right. This clause aims to restrict onward data sharing by ATPs. At first sight, it gives farmers inalienable control rights vis à vis third parties. However, farmers can give their consent in the agreement to leave it up to the ATP to decide on sharing data with third parties. Unlike in the GDPR, there are no details regarding the modalities of the consent. Is a general consent statement valid, and is there a right to withdraw consent? This might result in ambiguities with regard to the alienability of the right to consent. The primacy of contracts implies that withdrawal and data retention rights can also be restricted by agreements, i.e. they are alienable. Repetitive statements throughout the text in favour of contractual superiority may be an indicator of the ATPs' influence in designing the charter. ${ }^{95}$

60 The EU Code is again more ambiguous. Consent for data access and re-use may be given by the data originator or the operator. This boils down to the farmer's consent only if the farmer and originator coincide. Contract dominates, however, which implies that consent and re-use rights are alienable, as in the US charter.

"The collection, access, storage and usage of the collected agricultural data can only occur once the data originator has granted their explicit, express and informed permission via a

95 One may expect that industry stakeholders favour the status quo. They benefit from the existing non-regulatory environment with their de facto data control. The design of the EU and US charters that prioritise contractual freedom over the principles of the charters ensures this status quo. contractual arrangement." ${ }^{196}$

"The data originator must give permission for their data to be used and shared with third parties, including circumstances in which decisions are made based on data." 97

"Right to determine who can access and use the data is attributed to this operator." 98

"Parties ... should establish a contract clearly setting the data collection and data sharing conditions..." ${ }^{\prime 9}$

"Parties may not use, process or share data without the consent of the data originator." 100

61 Like in the US Principles, details of the consent conditions are not mentioned, apart from a reference to GDPR based principles such as being explicit, express and informed. Therefore, it is unclear if a general consent statement in the contract is valid or whether there is a right to withdraw consent. This example demonstrates the limitations of the contract-based design in the charters. The validity of contractual relationships can be challenged by using the explicit, express and informed permission argument as most of the service providers' terms and conditions are standard texts. So, the existing design is open to a number of problems in practice.

"Data originators must be given the possibility to opt-out of the contract and terminate or suspend the collection and usage of their data, provided that the contractual obligations have been met. This must be clearly stated in the contract..." ${ }^{101}$

62 This statement signals that the consent rights could be inalienable and can be cancelled at any time by the data originator. Not surprisingly, this general statement is again subject to contractual provisions. Unless stated in the contract, there is no right to opt-out or terminate. ${ }^{102}$ This problematic design is repeated all over the EU Code. It is difficult to see how these data principles could change anything if they would become law, compared to free and unregulated data markets, since contracts and market forces prevail over the principles.

96 The EU Code, n. 15, p. 9.

97 Ibid.

$98 \quad$ Ibid., p. 8.

99 Ibid.

100 Ibid.

101 Ibid., p. 10

102 Ibid. 
63 Another rule mentions pseudonymisation or anonymisation of agricultural data in the EU Code;

"Data originator must give permission for their data to be used and shared with third parties... Information should only be given to third parties as aggregated, pseudonymized or anonymised data unless it is required to deliver the requested service and/or the conditions specified in the contract. Unless specified in the contract, the data user must take all precautions to avoid re-identification." ${ }^{103}$

64 The concepts of pseudonymisation and anonymisation are related to the privacy and identifiability of natural persons. They do not have any meaning for non-personal agricultural data in this regard. Data could be anonymised with respect to the identification of the farm. Farmers might not be happy about other parties accessing data on their farming practices because it may affect the asset value of their farm, their credit score, etc. This may imply that farm identification and physical location coordinates should be eliminated from the data. It would be more appropriate to link the clear aims and the re-use consent requirements such as to protect farms' trade secrets, instead of using privacy law concepts.

65 Other principles in the US charter might also play a role in consent for access and re-use. For example, under "Transparency and consistency", it states that;

"ATPs shall notify farmers about the purposes for which they collect and use farm data, third parties to which they disclose the data and the choices the ATP offers for limiting its use and disclosure."

66 This formulation is not clear about the consequences of notification. Does the farmer have a right to object? The text is silent about this. The notification principle can become functional only if it is related to an inalienable consent right. Inalienability, in nature, is strictly related to binding legal rules that have clear enforcement mechanisms.

67 Under "Disclosure, Use and Sale Limitation" the US charter states that;

\footnotetext{
"An ATP will not sell and/or disclose non-aggregated farm data to a third party without first securing a legally binding commitment to be bound by the same terms and conditions as the ATP has with the farmer. Farmers must be notified if such a sale is going to take place and have the option to opt out or have their data removed prior to that sale. An ATP will not share or disclose original farm data with a third party in any manner that is inconsistent with the contract with the farmer. If the agreement with the third party is not the same as the agreement with the ATP, farmers must be presented
}

with the third party's terms for agreement or rejection."

68 This statement implies an extension of contractual terms to third parties. Since there is no in rem legal framework for data that is enforceable towards third parties, the US charter attempts to use contracts as an enforcement tool for these principles.

69 Both charters also have rules that prevent unilateral contractual changes without the consent of farmers.

70 The US Principles include the following statements:

“An ATP's principles, policies and practices should be transparent and fully consistent with the terms and conditions in their legal contracts. An ATP will not change the customer's contract without his or her agreement. "

71 The EU Code has the following consent rule:

"Contracts must not be amended without prior consent of the data originator. If data is to be sold or shared with a third party that is not initially mentioned in the contract, the data originator must be able to agree or refuse this, without financial or other repercussions." ${ }^{104}$

72 This protects farmers from unilateral actions. Service providers are obliged to maintain services under older terms and conditions (T\&C). Provisions that forbid unilateral changes are indeed stating the obvious because both of the charters are designed to be enforced via contracts, and unilateral changes are not compatible with the mutual assent principle in contractual relations in any case.

73 Apart from this general statement in the texts, the EU Code provides a specific obligation to take consent for the new data-sharing situations that are not specified in the contract beforehand. The originator can refuse new sharing. The obligation for service providers is not to impose any response to this refusal that would result in negative consequences for farmers. Although it is not clear what the scope of this obligation or the meaning of the negative repercussions exactly is, it is a positive intention to protect the weaker party in case of refusal decision for the third-party access. The prohibition of financial or other repercussions plays an important role to compel service providers or machine producers not to limit machine functionality, for instance, if new $\mathrm{T} \& \mathrm{C}$ are rejected. The US text has no statement regarding the consequences of such an action.

74 The EU Code brings an interesting obligation for third parties' access to data;

104 Ibid., p. 10

103 Ibid., p. 9. 
"The data user can only sell or disclose data to a third party if she/he has secured the same terms and conditions as specified in the contract between user and originator." 105

75 However, it is unclear whether this is an additional obligation above the ones discussed before or an alternative one to share data, or whether the farmer and third party enter into a direct contractual relationship or this is only between companies, i.e. data user and third party. In the case of the latter situation, it is difficult to see how a farmer can enforce its rights against the third party as the farmer would not be a part of the contract between companies. The idea seems to protect farmers with the same contractual conditions, but the existing form of the text is ambiguous.

76 In general, there are various consent rules to collect, access or re-use of data, especially in the EU code. However, neither their scope and enforcement mechanisms nor their effects on the competitive dynamics in the sector are undisputedly clear. Also, contractual superiority emphasis throughout the text further limits the potential of the proposed rules and rights, if any. Apart from the discussed ambiguities and limitations of the texts, the core question, indeed, might be whether we really need consent-based rules and rights in the non-personal agricultural data setting from the competition policy perspective. On the one hand, consent rights for collection, access and re-use of data might increase farmers bargaining position if they are inalienable and binding. On the other hand, this may create another set of barriers against the free flow of data in the sector. This balance should be carefully considered when designing the sectoral consent rules. Instead of transplanting personal data concepts from the GDPR, rights need to be designed in accordance with sectoral conditions. Data protection law serves a more human rightsoriented policy preference that might not always be compatible with the needs of the sector, which is predominantly based on non-personal agricultural data.

\section{Data Portability Designs and Lock-in Situations}

77 In the US Principles, data portability is considered as a privacy-related issue, not a competition issue because there is no portability right for anonymous or unidentifiable data sets. Also, only primary data can be ported, not 'aggregated' data;

"Within the context of the agreement and retention policy, farmers should be able to retrieve their data for storage or

105 Ibid. use in other systems, with the exception of the data that has been made anonymous or aggregated and is no longer specifically identifiable. Non-anonymized or non-aggregated data should be easy for farmers to receive their data back at their discretion."

78 As discussed above, anonymisation or identifiability are incompatible when discussing non-personal farm data as they are privacy law concepts. Protecting commercial confidentiality might have a certain rationale, but it is not related to the portability provision. When it comes to portability right, these nuances do not make sense. This indicates that the US Principles did not have a clear framework of failures to address them with their rules. It seems more like privacy-centric legal transplantation to an incompatible context, i.e. non-personal farm data.

79 The reference to "within the context of the agreement and retention policy" indicates that this is not an inalienable right. Farms can trade this right away in a contract, and market power will determine the eventual outcome of the negotiations. The US Principles actually do not change the status quo of the free B2B data market setting apart from its advisory statements in favour of contractual portability clauses.

80 In the EU Code, the rule regarding portability is as follows:

"Unless otherwise agreed in the contract, the data originator has the right to transmit this data to another data user. If agreed between the parties, the data originator shall have the right to have the data transmitted directly from one data user to another, where technically feasible."106

81 This demonstrates the approach of the EU Code in favour of the primacy of contracts over principles again. However, this clause has a different design compared to other rules in the text. In situations where contracts remain silent on portability, the Code could be invoked to assume portability by default. This makes the scope of portability right somewhat broader in the EU Code compared to the US Principles. This is still an alienable design as this right can be removed by contractual clauses. However, the following sentence repeats the same right by saying that if agreed between the parties. This makes the approach of the text confusing because this jeopardises the possible legal interpretation of default portability right in the case of contractual silence. The text could have been clearer in this regard.

82 Portability is only possible in the EU Code "where technically feasible" - again an explicit transposition from Article 20 (2) GDPR. Technical feasibility

106 Ibid., p. 9. 
might be problematic, especially when different and incompatible standards create an obstacle to the transfer. ${ }^{107}$ Differentiation in standards is sometimes an intentional business strategy to prevent portability of data to competitors. ${ }^{108}$ This may prevent farmers from enforcing their right even though the portability clause is not waived in the contract.

83 Indeed, the EU Code is aware of technical barriers to data portability and asks for transparency in this respect in the contract:

"The means through which they may migrate data pertaining to their farming operations to other service and the electronic data interchange standards and formats which are supported shall also be made clear." 109

84 Even though there is an obligation on service providers to be clear about standards and interoperability, this falls short of a sector-wide standard and interoperability obligation. This rule is more about a transparency obligation for service providers. Therefore, even though the proposed rule in the EU Code becomes binding, this will not be effective in removing potential technical barriers to the free flow of data and will not ensure interoperability in the sector.

85 The portability rule is complemented by the following paragraph;

"This should be done without compromising restricted access to machine data or sensitive data (only relevant to the correct functioning of the machinery). This should be clearly specified in the contracts between farmers/contractors and device manufacturers." ${ }^{110}$

86 This statement caters to the wishes of machine manufacturers to protect their proprietary, sensitive and confidential data collected, stored and processed in machines, including data regarding the operations of the machine itself. Service providers or machine producers' 'proprietary data' fall outside the data originators' rights to portability.

107 The technical feasibility of ag-data transfer/combination is discussed by computer scientists at Wageningen University. See 'DATA FAIR' (WUR, 2020) <https://www.wur.nl/en/article/ DATA-FAIR-EN.htm> accessed 4 March 2021. The authors state that portability is possible and meaningful if the data is findable, accessible, interoperable, and reusable.

108 This is one of the problems in the sector: "Every provider is building his own little kingdom." See Esmeijer and others, n. 74, p. 34; See also at Kritikos, n. 21, p. 10.

109 The EU Code, n. 15, p. 10.

110 Ibid., p. 10.
87 The EU Code also mentions the data formats when receiving data from service providers;

"The data originator shall have the right to receive the data concerning their operation as specified in the contract, in a structured, frequently used and machine-readable format." ${ }_{111}$

88 The reference to "the right to receive the data concerning their operation" associates data rights with farming operations, not with the machine or device ownership. As noted before, this is important in a sector where renting machines and outsourcing of services is a common practice. It somewhat reduces the ambiguity in the attribution of original rights to data originators. It is obvious that stakeholders in the EU are aware of technical challenges to transfer data due to lack of standards and fragmentation in data formats, and this general principle could have been helpful to mitigate this problem to a certain extent, if it had been binding.

89 As a general consideration, although existing forms of portability related provisions in both the EU and US charters are not adequate to mitigate sectoral concerns deriving from farmers' lock-in situations, one can expect that these voluntary portability rules might become a sector trend to implement more lenient data policies by service providers in terms of enabling the transfer of data to rivals when farmers desire to do so, especially for the EU Code as the US Principles are more focused on transplanting privacy principles rather than promoting competition in the market. However, it might not be realistic to expect that service providers will voluntarily renounce their exclusive control over the collected data. They have no incentive to weaken the advantages they derive from their exclusive data access. Still, the design of the EU Code, with a default portability right for farmers, ${ }^{112}$ unless repealed by contract, could be an important step towards inalienable and binding rights for farmers, compared to the US Principles in which contractual clauses are always considered superior to the proposed rules and principles.

\section{Other Rights and Rules on Data}

90 Our main focus in this section is to compare the attribution of original rights, data re-use/access rights and portability rights in these voluntary initiatives from a competition policy perspective. These rights could have major implications for data access related problems in the sector. However, it is also interesting to briefly evaluate other

111 Ibid., p. 9.

112 despite the ambiguity in the following sentence of "If agreed between the parties". Ibid., p. 9. 
provisions in the charters, such as data retention/ retrieval rights, purpose/storage limitation rules or prohibition of speculation and price discrimination. These may also affect the data access puzzle in this emerging sector. This sub-section discusses whether they are suitable for the non-personal machine agdata setting and address the identified concerns.

\section{Data Retention/Retrieval Rights}

91 In the US text, the following principle is proposed:

"Each ATP should provide for the removal, secure destruction and return of original farm data from the farmer's account upon the request of the farmer or after a pre-agreed period of time."

92 This statement seems inspired by the "right to be forgotten" in the EU GDPR. Farmers may want to exercise this right, for example, when they change service providers along with their portability right that is separately mentioned in the text. However, it is unclear what this provision aims to protect since farm data is not personal.

93 In the EU Code, there is a general statement about access and retrieval rights:

"Data originators should be granted appropriate and easy access and be able to retrieve their attributed ("own") data further down the line, unless the aggregated data is not linked to the attribution as it is not only based on the data of the data originator. It is essential to make the data provider ("collector") responsible for making the data easily available to the data originator in a format that they will find accessible and readable, where technically feasible. If not technically feasible, the data provider should provide justification." ${ }^{113}$

94 Data retrieval is applicable only to the original "attributed" farm data, not to the processed data sets that have been enrichened by other data sources. The rule is limited by technical feasibility constraints.

95 The EU Code also has a specific rule on 'right to be forgotten' beyond the general statement of retrieval rights;

"There must be the option to remove, destroy (e.g. right to be forgotten) or return all original data (e.g. farm data) upon the data originator's request." ${ }^{114}$

96 The "right to be forgotten" exists in the GDPR for personal data, including farmers' personal data. That right may be meaningful for non-personal business

113 The EU Code, n. 15, p. 9.

114 Ibid., p. 11. data to preserve commercial secrecy and prevent third-party access that could be harmful to the commercial interests of the farm. Indeed, the EU Code states that:

"Protecting trade secrets, intellectual property rights, and protecting against tampering are the main reasons as to why information is not shared and why even business partners in joint projects are not permitted to receive data." 115

97 However, the intention to address commercial concerns could have been stated more directly in both texts without using GDPR terminology.

\section{Purpose and Storage Limitations}

98 In the US Principles:

"An ATP will not share or disclose original farm data with a third party in any manner that is inconsistent with the contract with the farmer."

99 In the EU Code:

"Data must be collected and used for the specific purpose agreed in the contract. The datasets should only be kept for as long as is strictly necessary for the relevant analyses to be carried out. In addition, data should only be accessed by those with the required authorisation." 116

100 Purpose and storage limitations are again legal transplants from the GDPR. The EU Code links it with an implicit obligation for service providers to destroy the data after use. This may create complications when farmers store their historical data sets only in databases of service providers. Contracts will normally define retention periods. There is no explicit duty to inform farmers when data are about to be destroyed. This might be problematic. Purpose limitation rules may strengthen farmers' positions vis-a-vis service providers or machine producers, but this may also limit the potential societal welfare effect deriving from full data exploitation. Personal data related principles borrowed from GDPR should be carefully considered in the non-personal farm data setting when designing the related rules.

115 Ibid., p. 12

116 Ibid., p. 9. 


\section{Prohibition of Speculation and Price Discrimination}

101 Both the US Principles and EU Code contain prohibitions to use the data for unlawful and anticompetitive activities. They also go further and contain somewhat moralizing statements.

102 In the US Principles:

"ATPs should not use the data for unlawful or anti-competitive activities, such as a prohibition on the use of farm data by the ATP to speculate in commodity markets."

103 In the EU Code:

"Collectors and users of farm data must therefore not use this data for unlawful purposes or take advantage of it to speculate or for other such purposes." 117

104 The inclusion of speculation "or other such purposes" is strange. Speculation is not an unlawful activity. It may actually induce transparency and efficiency gains. Futures markets in agricultural commodities are an essential part of agricultural markets. We can infer that the statement in the EU Code intends to cover unfair behaviours such as the use of data for price discrimination purposes. ${ }^{118}$ It contains a prohibition of price discrimination:

"The data must not be used to assess the originators' ability to pay for a service." 119

105 Farm data may be used to assess farmers' willingness to pay for goods and services. This, in turn, can lead to price discrimination. Price discrimination is not a per se an infringement of competition law. ${ }^{120}$ Moreover, it can, under certain conditions,

117 Ibid., p. 11.

118 Here, exploitative abuse can come to mind as the fear seems to be related to charging higher prices for agricultural commodities according to the farmers' dependency on those particular products or inputs with the help of insights generated through aggregated farm data sets.

119 The EU Code, n. 15, p. 11.

120 Post Denmark I -Case C-209/10 EU:C:2012:172, para 30. See the situations where price discrimination can be exploitative of customers in Richard Whish and David Bailey, Competition Law (9th edn, Oxford University Press 2018), pp. 779-782. For an empirical study about price discrimination by powerful intermediaries, see, for example, Lauren Falcao Bergquist and Michael Dinerstein, 'Competition and Entry in Agricultural Markets: Experimental Evidence from Kenya' (2020) 110 American Economic Review. be welfare-enhancing ${ }^{121}$ for farmers and service providers. Obviously, farmers fear that powerful data companies could use the data against their interests, to manipulate or exploit them in inputs and outputs markets. Price discrimination is a strategy that allows sellers to extract more profits from buyers. It may reduce buyers' welfare but may also enable new buyers to come into the market when they receive more attractive price offers. As such, price discrimination induces equity concerns because of changes in welfare distribution. It may also generate additional welfare for society as a whole. The net balance between these two effects is an empirical question.

\section{General Considerations}

106 Although there are some positive considerations, ${ }^{122}$ attempts by the US and EU agricultural data charters to transpose some basic GDPR principles of personal data protection to non-personal machine-generated data run into several problems. For instance, notions of pseudonymization and anonymization or the right to be forgotten are related to the privacy of natural persons. They are not relevant for nonpersonal agricultural data. If the aim was to protect commercially sensitive data, it could have been stated more clearly without transplanting the GDPR concepts. In general, the absence of an obvious anchor for these rights in a natural person creates ambiguity with regard to the rights-holder: is it the farm or the farmer, or other parties?

107 These voluntary charters are naturally limited in terms of sector-wide validity and enforcement, except for the external auditing system in the US Principles. ${ }^{123}$ An additional limitation in both data charters is the primacy of contracts over principles. Rights can be limited and alienated from farmers by contracts even though a company declares its participation in the charters. Markets and bargaining power in contractual negotiations will determine the outcome despite the proposed rules/principles. Even if the EU and US regulators would turn the voluntary

121 Whish and Bailey, n. 120, pp. 777-778.

122 See, for instance, Jouanjean and others, n. 12 above, pp. 10 and 14-15.

123 There is a criticism about the ongoing practices of the Ag Data Transparent. See Mark R. Patterson, 'Ag Data Transparent, or Not' (antitrust.online, 2020) <https://antitrust.online/ commentary/> accessed 4 March 2021. 
principles proposed in the data charters into legally binding text, it is hard to see how they could correct B2B agricultural data market failures. ${ }^{124}$

108 These initiatives were not designed with a list of market failures and aftermarket competition concerns in mind. Instead, they transplanted rules designed to protect the privacy of individuals. One can, therefore, not expect these voluntary data governance initiatives in the US and EU to effectively address competition-related problems in this emerging sector.

\section{E. Alternative Ways Forward}

109 So far, we focused on situations where ag-tech machines are equipped with proprietary interfaces that collect data on devices and servers exclusively controlled by machine manufacturers or agronomic service providers. In the absence of data portability, farmers are locked into aftermarket services. They lose control over current and historical farm data. This monopolistic relationship distorts the market for data and related services.

110 In the previous section, we explored to what extent voluntary data governance initiatives based on agreements between farmers and agro-industry stakeholders could give farmers more choices. Our analysis demonstrated that contractual negotiations prevail in these agreements and leave farmers dependent on the goodwill of the providers of the services and devices that collect their data.

111 In this section, we first explore a market-based option: storing farm data with neutral third-party

124 It is important to note that the Australian Farm Data Code does not allow contractual freedom to overrule the principles of the Code. Participating companies have to follow the declared rules. However, it has its own limitations deriving from legal design and preferred wording. For instance, in the Australian Code's 'Portability of farm data', there is no obligation for service providers to directly transfer data to rivals. Another principle of the Code obliges providers to preserve farmers' ability to determine who can access and use data. It is not clear if this is a one-shot access to historical data or it also covers access to real-time data flows. See Australian Code, n. 17, pp. 3-4. The New Zealand initiative is more related to transparency than a list of principles or data rights. There is an obligation for participating companies to disclose their practice regarding matters such as data security, rights to data and access rights. It does not intervene in contractual relations between companies and farmers. See New Zealand Farm Data Code of Practice, n. 17. In this regard, it falls behind the other initiatives. intermediary platforms ${ }^{125}$ or data cooperatives ${ }^{126}$ that are not vertically integrated with machine or inputs producers. We then discuss the possibilities for regulatory intervention in agricultural data markets by assigning mandatory data rights, including data portability right for farms.

\section{Neutral Third-party Data Intermediaries}

$\mathbf{1 1 2}$ There is a wide variety of third-party intermediaries that operate in the agricultural data market. Some of them behave in a "neutral" way: they are not vertically integrated with machine producers, inputs suppliers or agronomic services providers. As such, they have no stake in the sales of these products and no incentive to use the data to promote these sales. Of course, there are various shades of neutrality: some are more neutral than others. They range from not-for-profit to purely commercial data intermediaries. Their common characteristic is that they offer farmers some degree of control over the management of their data, sometimes combined with the promise that they can monetise farm data or appropriate a larger share of the benefits that data can generate. These intermediaries have been referred to as "Agri-Business Collaboration and Data Exchange Facility" (ABCDEF), ${ }^{127}$ i.e. "neutral” B2B data platforms where farmers and agri-businesses can collaborate and exchange data in standardized formats. This could purportedly strengthen the position of farmers in the data market. The European Commission announced its support for the creation of "a common European agricultural data space to enhance the performance and competitiveness of the agricultural sector through the processing and analysis of production and other data, allowing for precise and tailored application of production approaches at farm level". ${ }^{128}$ This agricultural data space might also fall in the category of neutral intermediaries. However, no further details are known yet on this project.

125 See Eric A. Posner and E. Glen Weyl, Radical Markets: Uprooting Capitalism And Democracy For A Just Society (Princeton University Press 2018). The authors argue that data providers should create data unions, similar to labour unions, in order to extract a large value for their data contributions.

126 Apart from their potential to address competition concerns identified in this paper, there might also be other potential benefits as well as drawbacks of data cooperatives in agriculture. See Jouanjean and others, n. 12, p. 16.

127 See more in Poppe and others (2015), n. 2 above.

128 Communication from the European Commission "A European Data Strategy" COM (2020) 66. 
113 The intermediary would act as a Farm Information Management System (FIMS), ${ }^{129}$ comparable to Personal Information Management Systems (PIMS) ${ }^{130}$ that have been suggested for personal data. They fulfil several roles: data storage, identity and permissions management, service and monetization management, standardized and secure data transfers through APIs, compliance management and accountability.

114 Large agri-business firms with vertically integrated data services are a step ahead of FIMS because they already have a large user base that they can leverage to generate network effects in data collection and better service production. It is not easy for FIMSs to overcome this disadvantage, unless they have a large and vertically integrated market side too. Some agricultural cooperatives may be in that situation as they sell agricultural inputs and rent machines. However, that makes them commercial stakeholders in at least one market and undermines their neutral third-party status. In France, for example, the InVivo agricultural group has started from its strong market position in agricultural products to add a data management and analytical dimension to its business. ${ }^{131}$ There are many other examples of such intermediaries. ${ }^{132}$ Some of these intermediaries have vertically integrated with data analytics firms. In the US, for example, GISC (Growers Information Services Cooperative) is an agricultural data cooperative that teamed up with IBM for data storage in the cloud to produce data analytics services that generate value-

129 This notion has been discussed in the more technical data literature since 2012. See Alexandros Kaloxylos and others, 'Farm Management Systems and the Future Internet Era' (2012) 89 Computers and Electronics in Agriculture; Alexandros Kaloxylos and others, 'A Cloud-Based Farm Management System: Architecture and Implementation' (2014) 100 Computers and Electronics in Agriculture cited in Jan W. Kruize and others, 'A Reference Architecture for Farm Software Ecosystems' (2016) 125 Computers and Electronics in Agriculture, p. 14.

130 See 'Personal Information Management System' (edps.europa, 2020) <https://edps.europa.eu/data-protection/our-work/ subjects/personal-information-management-system_en> accessed 4 March 2021.

131 'Big Data and Agriculture | Invivo' (Invivo-group.com, 2020) $<$ https://www.invivo-group.com/en/big-data-and-agriculture/> accessed 4 March 2021.

132 Just to list a few: API-AGRO (https://api-agro.eu/en/) in France, DjustConnect (https://djustconnect.be/en/) in Belgium, DKE agrirouter (https://my-agrirouter.com/en/) in Germany, Agrimetrics (https://agrimetrics.co.uk/) in the UK, Farmobile (https://www.farmobile.com/) and Farm Business Network (https://www.fbn.com/analytics/datastorage-integration) in the US accessed 4 March 2021. added on top of handling raw data. ${ }^{133}$ Farmers pay for these services. This cooperative data business model retains some degree of neutrality with respect to products and services markets; it avoids selfpreferencing in these markets. IBM has no stake in selling agricultural machinery or inputs, and it is neutral in this regard. As such, it may allocate a larger share of data-driven value-added to farmers. However, we do not have any information on the possibility for farmers to switch their data to other service providers than IBM. ${ }^{134}$

$\mathbf{1 1 5}$ Other intermediaries have opted to stay neutral with regard to data analytics and use. They facilitate access and exchange of data but do not store or extract value from the data. For example, in the Netherlands, Join-Data is a not-for-profit agricultural data platform where farmers share their data with various agro-industry partners and companies that want to access data. ${ }^{135}$ JoinData is set up by some large Dutch dairy and meat cooperatives involved in processing and distribution of agricultural inputs and livestock products. Some commercial firms are also members, including a bank and an IT services company that created the technical platform. ${ }^{136}$ The platform manages data access authorisations for farms, but it does not store or analyse farm data. That is left to application providers. It is a mere passive and neutral data access \& distribution platform, not an active data-driven agronomic services provider. It facilitates the transmission of data between farm machines and data users, including distributors of inputs and outputs, downstream industries, databased agricultural service providers, with the authorisation of the farmer. JoinData membership terms \& conditions do not say anything on ownership or access to data because it takes no responsibility for the handling of data. JoinData seeks to improve farmers' trust by giving them more control over the use of their data at any time, by means of

133 See 'Home - Grower's Information Services Coop' (Grower's Information Services Coop, 2020) <https://www.gisc.coop/> accessed 4 March 2021.

134 See also potential limitations of farmers' data cooperatives from the perspective of the data lock-in problem. Atik, n. 29, pp. 67-68.

135 See, for instance, Join-Data at 'Data Sharing in the Agricultural Sector | Support Centre For Data Sharing' (Eudatasharing.eu, 2020) <https://eudatasharing.eu/examples/data-sharingagricultural-sector> accessed 4 March 2021.

136 It has several members including Friesland Campina (dairy) and Royal Agrifirm (a large cooperative provider of agricultural inputs), CRV, LTO, Royal Cosun, Avebe, Rabo Frontier Ventures, EDI-Circle (an IT firm in data management). See 'About Joindata - Joindata' (Join-data.nl, 2021) <https://joindata.nl/en/about-joindata/> accessed 4 March 2021. 
authorisations. Farmers do not pay for the service. Data users pay a fee for data communication, not for the data itself. It does not build data interfaces to facilitate data portability. Application providers have to build their own interfaces. It uses the AgroConnect data standard for data transmission and for its APIs. ${ }^{137}$ Most members of AgroConnect are active in downstream data-driven services; some are manufacturers of machines and sensor devices. ${ }^{138}$

116 This model comes closest to a neutral third-party data intermediary. It gives farmers more control over who can access and use their data, reduces switching costs and avoids data lock-in for farmers. Farmers gain more subjective control over their data. That does not necessarily translate into capturing more value-added from agronomic services. That still depends on the farmer's bargaining power with agro-service providers. It does not overcome the restrictions imposed by contracts between farmers and machines producers that may prevent them from accessing or porting their data, or may lock them into incompatible data formats. JoinData can only work when the original agreement with the data source (machine producer) allows it.

\section{Neutral third-party data intermediaries face two major hurdles:}

117 First, they require access to data sources. For example, the JoinData model works to the extent that data sources (machine producers) allow JoinData to manage the portability of their machine data. What would be their incentive to give away their exclusive access and allow other service providers to use their data? We can find some tentative answers to that question when looking at the membership list of JoinData's data interoperability standard, AgroConnect. Members are mostly downstream agricultural services providers, ${ }^{139}$ not upstream producers of data collection machines. The few exceptions are small machine and sensor producers that have very little to gain from maintaining data exclusivity. Their business model consists of selling machines and sensors, not selling data-driven analytics. We find the same pattern in membership of the more widely used Isobus interoperability standard for agricultural machines: only smaller

137 See 'Member List' (Agroconnect.nl, 2020) <https://www. agroconnect.nl/overagroconnect/ledenlijst.aspx> accessed 4 March 2021.

138 See Ibid.

139 Ibid machine manufacturers adhere to it while none of the larger ones do, except for a few of their machines in markets where they are not leaders. ${ }^{140}$ This is in line with the predictions from economic theory. ${ }^{141}$ When a platform is small, it can only gain from interoperability. Conversely, if the platform is large, gain from interoperability will be limited while its competitor will gain more. Consequently, dominant platforms' incentives to accept interoperability will be low.

118 Second, they need to overcome several economic hurdles, similar to PIMS. ${ }^{142}$ The parties (farmers, companies and platform operator) must find a sustainable data business model. That may be problematic. Farmers may not be willing to pay for storing and managing their raw data through FIMS, unless they receive well-defined monetary benefits in return. Some farmers may be motivated by the subjective feeling of more control over their data, independently of any monetary gains. Farmers may expect payment for the use of their raw data by agroindustry firms. This is unlikely to happen because the marginal value of individual farm data may be close to zero for a service provider as soon as it has reached a sufficiently large data pool where the marginal return to economies of scale and scope in aggregation come close to zero. That is why farmers usually have to pay a price for access to data-driven services, even if they deliver their own data to that service provider. New entrants in the data-driven services markets may subsidise data control services for farmers in order to attract more clients. This may be the case for JoinData. Eventually, however, full costs will have to be reflected on one or the other side of the market.

119 For data cooperatives, the only viable business model seems to require the production of data-based valueadded services on top of the raw data delivered by farmers. This requires investment in data analytics as, for example, the case of the GISC in the US that collaborates with IBM to produce data-driven insights. Only large cooperatives with a sufficient volume of data collection can achieve the necessary economies of scale and scope in data aggregation to produce efficient data-driven services.

120 These economic considerations lead us to the conclusion that neutral third-party intermediaries are likely to remain outside the mainstream agricultural data market. It also raises questions

140 See 'Members' (CC-ISOBUS, 2020) <https://www.cc-isobus. com/en/das-cci/> accessed 4 March 2021.

141 Crémer, Rey and Tirole, n. 31 above.

142 See more about PIMS, for example, in Krämer, Senellart and de Streel, n. 63, pp. 66-75. 
about the potential benefits and limitations of voluntary interoperability and whether mandatory standards are necessary to overcome data-related competition bottlenecks in agricultural markets. We address this question in the next section.

\section{Regulatory Intervention with Mandatory Rules}

121 In this section, we explore regulatory intervention as an alternative to overcome exclusive data access by device manufacturers and agronomic service providers. Data portability and/or interoperability is a necessary technical condition to unlock farm data. ${ }^{143}$ However, it does not answer the question of who can use the portability or access rights and under which conditions. That is an important question because it affects the welfare of stakeholders in the agricultural production process. Policymakers can introduce mandatory portability to increase the joint welfare of farmers, agricultural industry and service providers, and consumers. The impact on these groups may not be evenly distributed, however, and can create equity and fairness concerns.

122 For personal data, the data subject as a natural person and originator of the data is the obvious rights holder and the basis for data protection rights in the GDPR. We argued in Section $C$ that there is no equivalent for non-personal farm data, unless there is only one single data originator. When several parties contribute to an agricultural production process, they may all claim access rights to at least part of the data. Landowners may claim access to land use data from tenant farmers. Machine rental companies may compile usage data. Machine producers may collect data from all their machines. Agronomic service providers may collect data from all their client farms. Data analytics and other external service providers may claim use rights on the data that they process.

123 Some authors have suggested to distinguish between volunteered, observed and inferred data as a way to allocate data access rights. ${ }^{144}$ Volunteered data have been willingly contributed by a user to service providers. For example, farms share their land and soil maps with rented seeding, fertilizer and harvest machines. Observed data are the result of interactions between users and the service provider. For example, combine harvesters

143 See, for instance, Jouanjean and others, n. 12, p. 18.

144 Jacques Crémer, Yves-Alexandre de Montjoye and Heike Schweitzer, 'Competition Policy for the digital era - Final Report' (Publications Office of the European Union 2020), pp. 24-29. collect data on the quantity of crops harvested. Fertilizer machines observe the type and quantity of chemicals used. Volunteered and observed are raw primary data. Inferred data are derived from raw data and produced by a data service provider by means of algorithms or other calculations and transformations. For example, raw land \& soil maps and cropping pattern data are inputs for algorithms that recommend chemicals for crop protection. Combined with harvesting data, they can evaluate the productivity of a farm. Apart from the fact that the distinction between these three categories is not always clear, this categorisation does not resolve the question of who should get access to which type of data and under what conditions.

124 Currently, in the EU, portability right exists only for personal data in the GDPR. Even this right has significant limitations. ${ }^{145}$ A very limited legal notion of portability right for non-personal data is mentioned in the Free Flow of Data Regulation, ${ }^{146}$ only for cloudbased data services and on a voluntary basis through sectoral codes of conduct to be negotiated between industry stakeholders. In other words: it merely endorses the existing EU agricultural data charter. Other sectoral precedents for portable machine data exist, for example, in automotive, ${ }^{147}$ energy ${ }^{148}$ and payments services. ${ }^{149}$

145 See, n. 63 above.

146 Regulation (EU) 2018/1807 of the European Parliament and of the Council of 14 November 2018 on a framework for the free flow of non-personal data in the European Union, OJ L 303, 28.11.2018, Article 6.

147 Regulation 2018/858 of the European Parliament and of the Council of 30 May 2018 on the approval and market surveillance of motor vehicles and their trailers, and of systems, components and separate technical units intended for such vehicles, amending Regulations (EC) No 715/2007 and (EC) No 595/2009 and repealing Directive 2007/46/EC, OJ L 151/1, 14.6.2018, Articles 61-66.

148 Directive 2019/944 of the European Parliament and of the Council of 5 June 2019 on common rules for the internal market for electricity and amending Directive 2012/27/EU (recast), OJ L 158/125, 14.6.2019, Article 23.

149 Directive 2015/2366 of the European Parliament and of the Council of 25 November 2015 on payment services in the internal market, amending Directives 2002/65/EC, 2009/110/ EC and 2013/36/EU and Regulation (EU) No 1093/2010, and repealing Directive 2007/64/EC, OJ L 337/35, 23.12.2015, Articles 66-67. 
125 The proposed Data Governance Act ${ }^{150}$ includes regulation of data sharing services. Article 9 restricts the application of the regulation to three categories of data intermediaries: providers of bilateral or multilateral data exchange services, personal data sharing services and data cooperatives. Recital 22 explains that providers of data sharing services are specialised intermediaries that are independent from both data holders and data users. They assist both parties in their transactions of data assets. It covers services that intermediate between an indefinite number of data holders and users, not closed groups or an exchange platform that is exclusively linked to services provided by one data holder. It also excludes IoT data platforms that connect machines and devices, and services that generate value-added from the transformation and analysis of data without a direct relationship between data holders and users. We could not find any type of agricultural data service provider that would still fall within this very narrow definition of data sharing services. This leaves the category of data cooperatives as an alternative option. However, this category is not defined in the regulation. Even if there would be any agricultural data platforms that could be considered as data intermediary services under Article 9, the conditions that apply to these platforms under Article 11 are very general and do not go beyond what is already foreseen in the EU code of conduct that is investigated in detail in the section above.

126 The Digital Markets Act (DMA) ${ }^{151}$ defines mandatory B2B data sharing obligations for (non-personal) commercial data. This applies only to very large "gatekeeper platforms" that provide "core platform services". Agricultural data services are not covered by these DMA definitions. However, it is worth noting that DMA Article 6(h) introduces a real-time data portability right for business users on gatekeeper platforms. Article 6(i) mandates free access for business users to non-personal commercial data provided and generated by their activities on the platform. These articles introduce data access and portability rights for legal entities (i.e. businesses). Moreover, they go beyond the GDPR by abolishing any delays and mandating real-time access.

$\mathbf{1 2 7}$ These clauses constitute a first step towards portability rights for non-personal commercial business data in the EU. While the DMA does not apply to agricultural data platforms, the European

150 Proposal for a Regulation (COM/2020/767 final) of the European Parliament and of the Council on European data governance (Data Governance Act), 25.11.2020.

151 Proposal for a Regulation (COM/2020/842 final) of the European Parliament and of the Council of on contestable and fair markets in the digital sector (Digital Markets Act), 15.12.2020.
Commission announced its intention to prepare proposals for a Data Act in 2021. It would include general regulatory provisions for B2B sharing of non-personal and machine-generated data. ${ }^{152}$ The details of this proposal are not known yet.

128 We can explore the conditions under which nonpersonal data portability rights could work for farms as business entities ${ }^{153}$ and how this could increase competition in aftermarket services. In a simple one-to-one relationship between a farm and a machine or device producer, real-time portability and interoperability of machine data would separate primary machine markets from aftermarket services. It would enable farmers to select any aftermarket service provider of their choice. This would increase competition in aftermarkets. For example, a tractor or seeding machine could be steered by data-driven services from any provider. However, it would not prevent service providers from re-using the data for other purposes or sharing them with other businesses, unless re-use would be subject to consent from the farm to which the data pertain. One could think of a farm-centric portability and re-use right, limited to farms only and excluding other parties.

129 Exclusive rights for farms become complicated when more parties are involved in the agricultural production process. The farm's central role in data collection may be eroded by competing data access claims from other parties. For example, machines can be owned by leasing firms, farmland can be owned by another party, farm data analytics and agronomic advisory services can be performed by a third party, etc. Leasing firms can claim access to machine data to monitor the use and performance of their machines; land owners may claim access to data on agricultural activities to monitor the quality of their land; and agronomic advisory services firms may claim rights over the service data that they produce. This leads to a debate on who gets access to which data under which conditions. Leasing firms may be granted access to mechanical machine data only, not to the quantity and quality of agricultural inputs and outputs. Land owners may, however, want to access data on the quantity and quality of inputs and outputs because that affects the quality and value of their land. Once these parties obtain a right to access these data, they may also claim the right to re-use the data without the consent of the farm.

152 See 'Legislative Train Schedule | A Europe Fit For The Digital Age' (European Parliament, 2021) <https://www.europarl.europa.eu/legislative-train/theme-a-europe-fit-for-the-digitalage/file-data-act> accessed 4 March 2021.

153 Focusing on farms as legal persons instead of farmers as natural persons is important for the effectiveness of the portability design in the sector. See section D.I above. 
130 Data access and re-use by other parties is valuable from a social welfare perspective. It enables these parties to improve the efficiency and economic value of their activities. At the same time, re-use may also impact the farm. Detailed land use data can affect the value of farmland and the creditworthiness of the farm. More reliable valuations are beneficial for society but not necessarily for the farm as a private undertaking. They may be used for price discrimination and speculation that are explicitly rejected in the EU code of conduct.

131 Like intellectual property rights, data need to have some degree of excludability in order to retain their market value. Making them widely available reduces their value to near-zero. ${ }^{154}$ However, it may increase competition in downstream services markets, reduce prices and increase service quality. That may have positive welfare effects on farms via the services price channel. More competition in data-driven aftermarket services would help farmers to appropriate a larger share of data-driven productivity gains through lower prices and better service quality. ${ }^{155}$

132 The design of data access regimes is squeezed between two extremes. On the one hand, granting exclusive rights to farms when many parties contribute to the agricultural production process is not an optimal solution. On the other hand, generalised data portability and re-use for all is not ideal when negative externalities occur between parties. An intermediate solution that keeps some restrictions may be required to preserve the rights and welfare of some parties. All this indicates that a data access regime should be tailored to specific situations.

133 Smith warns us that the cost of intermediate data governance or data pooling regimes can be very high compared to the much lower costs of private ownership rights or fully open public domain regimes. ${ }^{156}$ However, each of these cheaper regimes has its own costs. Public domain or full data sharing regimes may lead to underinvestment for lack of

154 Dirk Bergemann and Alessandro Bonatti, 'Markets for Information: An Introduction' (2018) CERP Discussion Paper - N. DP13148; Bergemann, Bonatti and Gan, n. 57 above.

155 For a theoretical economic model that arrives at this conclusion, see, for example, Paul Belleflamme and Martin Peitz, 'Platforms and Network Effects' in Luis C. Corchón and Marco A. Marini (eds), Handbook of Game Theory and Industrial Organization, Volume II (Edward Elgar 2018).

156 Henry Smith, 'Toward an Economic Theory of Property in Information' in Kenneth Ayotte and Henry E. Smith (eds), The Research Handbook on the Economics of Property Law (Edward Elgar 2011). private incentives while exclusive private ownership data regimes lead to underutilisation of resources. Expensive data governance regimes should only be implemented if the benefits to society exceed the cost of governance.

\section{F. Summary and Conclusions}

134 The arrival of digital data in agriculture opens the possibility to realize productivity gains through precision farming. It also raises questions about the distribution of these gains between farmers and agricultural service providers. It is tempting to believe that farmers can appropriate a large share of these gains when they remain in control of farm data. The reality of data-driven agricultural business models is that manufacturers of agricultural machines and devices design the data architecture in such a way as to retain exclusive control over access to the data. That enables them to foreclose downstream agricultural services markets that depend on these data. Also, agricultural technology providers' de facto control on the historical farm data sets locks their customer farmers in their systems due to the lack of a clear mechanism to force these companies to transfer the related data when farmers desire to switch service providers. This reduces competition in these markets and may increase prices which eventually reduces farmers' welfare.

135 Personal data protection regulation with its right to data portability is not applicable to non-personal agricultural machine data. Other existing regulations do not have any undisputedly equivalent mechanism to unchain farmers. Attempts to introduce voluntary data charters in the EU and US that emulate GDPRlike principles and purport to give farmers more control over their data have not been successful so far. Market-based outcomes still take precedence over farmers rights enshrined in the contracts. Farmers' bargaining power is reduced because thirdparty data platforms are a necessary intermediary to realize economies of scale and scope from data aggregation in addition to the fact that farmers need tailored data-driven prescriptions/solutions generated through these intermediaries' advanced algorithms. Farmers cannot achieve these benefits on their own. The low marginal value of individual farm data and farmers' need for tailored data-driven services put farmers in a weak bargaining position. For-profit and non-profit intermediaries that are not vertically integrated into agricultural machines, inputs or services, or pure data cooperatives, have tried to offer better deals to farmers. However, they can only circumvent monopolistic data lock-ins when they can access the data sets. That depends on the goodwill of the machine manufacturers or agronomic service providers. Moreover, they may 
have a hard time to achieve economies of scale and scope in data analytics and generate additional datadriven value-added. Without that, their business model may not be sustainable.

136 This leaves regulatory intervention as a last resort with mandatory data portability and interoperability to overcome data lock-in and monopolistic market failures. That inherently raises the question of the allocation of access rights: who should get access rights to which data and under which conditions? This is complicated when many parties contribute data to the production process and may claim access rights. Minor changes in who gets access to which data under which conditions may have significant effects on stakeholders. There is no clear answer yet to these questions. We conclude that digital agriculture still has some way to go to reach equitable and efficient solutions for detailed data access rights.

137 The European Commission's forthcoming proposals for a Data Act will have to address these issues in order to set the conditions for access to and sharing of nonpersonal machine data in a wide range of industries where hardware devices are used in Internet-ofThings settings. Regulators should design regimes with a view to maximise social welfare for society as a whole, not the private welfare of individual stakeholder groups. 